\title{
SWITCHING VOLATILITY IN INTERNATIONAL EQUITY MARKETS
}

\author{
Raul Susmel \\ University of Houston \\ Department of Finance \\ C. T. Bauer College of Business \\ Houston, TX 77204-6282 \\ (713) 743-4763 \\ FAX: (713) 743-4789 \\ e-mail: rsusmel@uh.edu
}

May 1999

\begin{abstract}
We analyze the behavior of time-varying volatility, when structural changes are allowed in international stock markets. We use a model developed by Hamilton and Susmel (1994), the SWARCH model, which is a more general specification than the popular ARCH model. We fit an exponential SWARCH model to eight series of weekly returns from international stock markets. We find evidence for switching volatility for the U.S., Canada, the U.K., and Japan. Under the SWARCH model, we find that ARCH and asymmetric effects are reduced when a switching regime structure is allowed. We use the switching model to date volatility states in international stock markets. We compare these states and conclude that domestic volatility states tend to be independent of foreign volatility states, with the exception of Japan and the U.K., and the U.S. and Canada. For these two pairs of series, we find evidence for common volatility states.
\end{abstract}

JEL: C53, G15

Keywords: Volatility, ARCH, switching, structural change.

* I am grateful to Jim Hamilton, Bob Pavlik, Robert Berry, and an anonymous referee for their useful comments. 


\section{I.- INTRODUCTION}

The seminal paper of Engle (1982) introduced the ARCH (autoregressive conditionally heteroskedastic) model. Later, Bollerslev (1986) generalized the ARCH model by introducing the GARCH model. The ARCH family of models has been applied successfully to financial data and has become one of the most popular tools to study financial markets volatility. A usual result of ARCH models is the highly persistent behavior of shocks to the conditional variance. This persistence, however, is not consistent with the results of recent papers that analyze the volatility after the Crash of October 1987, see Schwert (1990) and Engle and Mustafa (1992). Lamoreux and Lastrapes (1990a) argue that the near integrated behavior of the conditional variance might be due to the presence of structural breaks, which are not accounted for by standard ARCH models. Rare events such as market crashes, financial panics, changes in government policies, have a clear effect on many financial series. During these events, the volatility of such series changes substantially. For example, Schwert (1990) notes that stock volatility is higher during recessions. Even though the effect of a rare event, like a market crash, might be temporary, the magnitude of a rare event can have very serious effects on the estimation of time series models. Following the work of Hamilton (1989) on switching regimes, Hamilton and Susmel (1994) propose a new ARCH model, the Switching ARCH or SWARCH model. This model captures more realistically the time-series properties of dramatic economic events such as a stock market crash. In this model, volatility depends on past news and the state of the economy.

In this paper, we apply the SWARCH model to explain volatility in six international stock markets and two world stock indices. We use a new SWARCH model, the exponential SWARCH or E-SWARCH model. Then, we compare the E-SWARCH model with the E-GARCH model proposed by Nelson (1991). The comparison of both models is very simple. First, we fit different GARCH and SWARCH specifications. Second, we choose the best model of each class based on likelihood ratio tests. Then, we calculate out-of-sample variance forecasts for both models. We find evidence for switching volatility in the 
U.S., Canada, the U.K, and Japan. We find that compared to the GARCH-t model, the forecasting benefits of the SWARCH model are at best marginal. The out-of-sample variance forecasts of the GARCH-t model tend to be superior to the SWARCH forecasts.

As shown in Hamilton (1989), and pointed out by Goodwin (1993), the most innovative aspect of the Hamilton switching model is the ability to objectively date the states of the economy. Based on this observation, we date different volatility states for each series. Then, we use the volatility states to provide a different perspective on the nature of linkages among international stock markets. Some studies, for example, von Furstenberg and Jeon (1989), claim that stock markets around the world have become more integrated. Under the integration hypothesis, markets should experience similar reactions to common shocks. The simultaneous decline of world stock markets during the October 1987 Crash exemplifies this increased integration. During the days surrounding the Crash, stock market volatility dramatically increased in world markets. The effects of the 1987 Crash, however, were temporary and since then, the evidence of increased international linkages across markets is weak. These studies are based on mean returns correlations. Instead, we examine variance interrelations. Using the SWARCH estimates we study the interrelations of volatility states. King and Wadhwani (1990) argue that pricing mistakes might spread through international financial markets. An important part of their model is that this contagion effect increases with market volatility. Along these lines, it is possible to observe dependent high volatility states among countries. Hamao, Masulis and Ng (1990) find evidence of "volatility spillovers" among the U.S., Japan and the U.K. This finding seems to confirm a positive correlation of high variances in international stock markets. We find, however, that among the three biggest stock markets, only Japan and the U.K. have evidence of dependent volatility states and, among the regional markets, only the U.S. and Canada seem to have dependent volatility states. For these two pairs we find evidence of common volatility states.

The plan of the paper is as follow. In section II we present the family of Switching ARCH models 
with a two-state example. In section III we describe the model used in this paper and then we present the empirical results. Section IV summarizes the results.

\section{II.- SWITCHING ARCH MODELS}

Consider a simple E-GARCH(p,q) process for $\mathrm{y}_{\mathrm{t}}$,

(1) $y_{t}=f\left(\mathbf{x}_{t} ; \boldsymbol{B}\right)+e_{t}$

$\mathrm{e}_{\mathrm{t}} \mid \Psi_{\mathrm{t}-1} \sim \mathrm{D}\left(0, \mathrm{~h}_{\mathrm{t}}\right)$

(2)

$$
\begin{aligned}
& \ln \left(h_{t}\right)=\alpha_{0}+\sum_{i=1}^{p} \beta_{i} \ln \left(h_{t-i}\right)+\sum_{i=1}^{q} g\left(\frac{e_{t-i}}{\sqrt{h_{t-i}}}\right), \\
& \left.g\left(\frac{e_{t-i}}{\sqrt{h_{t-i}}}\right)=\varepsilon_{i} \frac{e_{t-i}}{\sqrt{h_{t-i}}}+\alpha_{i}\left(\frac{\left|e_{t-i}\right|}{\sqrt{h_{t-i}}}-\sqrt{(} 2 / \pi\right)\right),
\end{aligned}
$$

where $f\left(\mathbf{x}_{\mathrm{t}} ; \boldsymbol{B}\right)$ refers to the conditional mean, $\mathbf{x}_{\mathrm{t}}$ is a vector of $\mathrm{M}$ explanatory variables, that may include lagged $\mathrm{y}_{\mathrm{t}} \mathrm{s}, \boldsymbol{B}$ is a Mx1 vector of parameters, $\Psi_{\mathrm{t}-1}$ is the information set that contains all information available through time $\mathrm{t}-1$, and $\mathrm{e}_{\mathrm{t}}$ is the error term, which follows, conditional on $\Psi_{\mathrm{t}-1}$, a D distribution. The conditional errors have a zero mean and a time-varying variance, $h$. The conditional variance, $h$, follows an E-GARCH(q,p) process, as given in equation (2). As a conditional distribution, D, the normal, the Student-t and the Generalized Error Distribution (GED) are generally used. For example, Bollerslev (1987) proposed the Student-t and Nelson (1991) used the GED. Equation (2) displays an asymmetric effect of negative news on the variance, or leverage effect. Black (1976) relates the asymmetric effect of negative news to the fact that a negative price change increases the leverage ratio of a firm and, thus, increases the risk of the firm. In equation (2), the leverage effect is captured by the introduction of the level of past errors relative to their standard deviation. ${ }^{1}$

1 A popular GARCH(q,p) model with a leverage effect was proposed by Glosten, Jagannathan and Runkle (1993), hereafter GJR:

$$
h_{t}=\alpha_{0}+\sum_{i=1}^{q} \alpha_{i} e_{t-i}^{2}+\sum_{i=1}^{p} \beta_{i} h_{t-i}+\varepsilon L_{t} e_{t-1}^{2} \text {, where } \quad \mathrm{L}_{\mathrm{t}}=1 \text { if } \mathrm{e}_{\mathrm{t}-1}<0, \mathrm{~L}_{\mathrm{t}}=0 \text { otherwise. }
$$

In the above equation, the coefficient captures the asymmetric effect of negative surprises. Under the leverage effect hypothesis, will be positive. Equation (3) describes a GARCH(q,p)-L model. Engle 
ARCH models have been successfully applied to financial time series, Bollerslev et al. (1992) cite over two hundred applications to financial data. Lamoreux and Lastrapes (1990a), however, argue that ARCH estimates are seriously affected by structural changes. This might explain why ARCH models show an extremely high degree of persistence, weak forecasting and a poor statistical description of outliers. As stated in the introduction, many economic series show clear evidence of changes of regime. During these changes of regime, the behavior of the series sometimes changes dramatically. Suppose that large volatility shocks are infrequent and short-lived. We can think as these series having two states: a short-lived high volatility state and a long-lived normal volatility state. An ARCH model cannot capture these sudden volatility changes, given the autoregressive nature of the ARCH process. It underestimates the conditional variance at the time of the change from a normal volatility state to a high volatility state and overestimates the conditional variance when the economy goes back to the normal state.

Work by Hamilton (1989) offers a more realistic approach to modeling time series with changes of regime. In his simple, two state process, Hamilton assumes the existence of an unobserved variable, $s_{t}$, which can take two values: one or two. The variable $s_{t}$ describes the state of the economy. He postulates a Markov chain for the evolution of the unobserved variable:

$$
\begin{aligned}
& \mathrm{p}\left(\mathrm{s}_{\mathrm{t}}=1 \mid \mathrm{s}_{\mathrm{t}-1}=1\right)=\mathrm{p}_{11} \\
& \mathrm{p}\left(\mathrm{s}_{\mathrm{t}}=2 \mid \mathrm{s}_{\mathrm{t}-1}=1\right)=\mathrm{p}_{12} \\
& \mathrm{p}\left(\mathrm{s}_{\mathrm{t}}=1 \mid \mathrm{s}_{\mathrm{t}-1}=2\right)=\mathrm{p}_{21} \\
& \mathrm{p}\left(\mathrm{s}_{\mathrm{t}}=2 \mid \mathrm{s}_{\mathrm{t}-1}=2\right)=\mathrm{p}_{22},
\end{aligned}
$$

where $\mathrm{p}_{\mathrm{ij}}$ is the probability that the economy switches at time trom state $\mathrm{i}$ to state $\mathrm{j}$. It is convenient to summarize this transition probabilities in a $(2 \times 2)$ matrix $\mathrm{P}$.

Within this change of regime framework, Cai (1994), Brunner (1991), Hamilton and Susmel (1994),

and $\mathrm{Ng}$ (1993) find that the $\operatorname{GARCH}(1,1)-\mathrm{L}$ and the $\operatorname{E-GARCH}(1,1)$ are the best models to describe the leverage effect on the variance. 
and Hall and Sola (1996) modify the conditional variance equation (3) to make the conditional variance dependent on the state of the economy. In particular, Hamilton and Susmel (1994) reformulate equation (3) as follows:

(3) $\frac{h_{t}}{\gamma_{s_{t}}}=\alpha_{0}+\sum_{i=l}^{q} \alpha_{i} \frac{e_{t-i}^{2}}{\gamma_{s_{t-i}}}+\frac{\varepsilon}{\gamma_{s_{t-l}}} e_{t-1}^{2}$,

where the 's are scale parameters that capture the change in regime. One of the switching parameters, the 's, is unidentified and, hence, $\quad 1$ is set equal to 1 . In equation (3), the conditional variance depends on past shocks and the present and past states of the economy. Equation (3) also includes GJR-leverage state dependent effect. Inclusion of exogenous variables whose coefficients also depend on the state of the economy is straightforward.

Equation (3) represents a SWARCH(K,q) model, which allows for two states and q autoregressive lags. Equation (3) allows for sudden changes both in the constant and in the ARCH coefficients. Suppose there are only 2 volatility states. A sudden change to a high volatility state, with $2>1$, will increase the constant and the weights on past news. Under this specification, past shocks will have a bigger weight in the presence of a change to a high variance state. This approach has a limitation. The conditional variance should follow an $\operatorname{ARCH}(q)-L$ process and not a $\operatorname{GARCH}(p, q)$ process because the conditional density can only depend on a finite number of past values of $y_{t}$ and $s_{t}$.

A more general formulation, allowing for $\mathrm{K}$ states, is the $\mathrm{SWARCH}(\mathrm{K}, \mathrm{q})$ model. Suppose that $\mathrm{s}_{\mathrm{t}}$ can be described by a Markov chain:

(4) $\operatorname{Prob}\left(\mathrm{s}_{\mathrm{t}}=\mathrm{j} \mid \mathrm{s}_{\mathrm{t}-1}=\mathrm{i}, \mathrm{s}_{\mathrm{t}-2}=1, . ., \mathrm{y}_{\mathrm{t}-1}, \mathrm{y}_{\mathrm{t}-2}, ..\right)=\operatorname{Prob}\left(\mathrm{s}_{\mathrm{t}}=\mathrm{j} \mid \mathrm{s}_{\mathrm{t}-1}=\mathrm{i}\right)=\mathrm{p}_{\mathrm{ij}}$, for $\mathrm{i}, \mathrm{j}=1,2, \ldots, \mathrm{K}$.

Now, let the conditional variance equation be given by (3) but ${ }_{k}$, where $\mathrm{k}=1, \ldots, \mathrm{K}$, with ${ }_{\mathrm{k}}$ set equal to zero.

Hamilton and Susmel (1994) describe the algorithm used to evaluate the sample log likelihood function, which is maximized numerically. The distribution of the conditional errors can be the normal, the Student-t 
or the GED.

An E-GARCH like formulation of the $\operatorname{SWARCH}(\mathrm{K}, \mathrm{q})$ model can be achieved by rewriting equation (3),

(5) $\ln \left(h_{t}\right)=\ln \left(\gamma_{s_{t}}\right)+\alpha_{0}+\sum_{i=1}^{q} \alpha_{i} \frac{\left|e_{t-i}\right|}{\gamma_{s_{t-i}}}+\varepsilon \frac{e_{t-1}}{\gamma_{s_{t-1}}}$

As in the E-GARCH framework, no nonnegativity restrictions are necessary. Nonnegativity restrictions are important in the SWARCH model. Hamilton and Lin (1996), for example, impose ${ }_{1}=0$ in their SWARCH-L model for U.S. stock returns. We call the model in equation (5) E-SWARCH(K,q). In the ESWARCH(K,q) model, the conditional variance also should follow an E-ARCH(q) process and not EGARCH(q,p) process. Thus, the E-SWARCH model and the E-GARCH model are not nested. Moreover, in this E-SWARCH formulation, the autoregressive terms are not the standardized residuals. The EGARCH model has a longer memory, given by the inclusion of $\mathrm{h}_{\mathrm{t}-1}$, than the E-SWARCH model.

Hamilton (1989) describes how to make inferences about the particular state the economy was in at date $\mathrm{t}$. The filter probabilities, $\mathrm{p}\left(\mathrm{s}_{\mathrm{t}}, \mathrm{s}_{\mathrm{t}-1}, \ldots ., \mathrm{s}_{\mathrm{t}-\mathrm{q}} \mid \mathrm{y}_{\mathrm{t}}, \mathrm{y}_{\mathrm{t}-1}, . ., \mathrm{y}_{-3}\right)$, denote the conditional probability that the date $\mathrm{t}$ state was the value $\mathrm{s}_{\mathrm{t}}$, the date $\mathrm{t}-1$ state was the value $\mathrm{s}_{\mathrm{t}-1}, \ldots$, and the date $\mathrm{t}-\mathrm{q}$ state was the value $\mathrm{s}_{\mathrm{t}-\mathrm{q}}$. These probabilities are conditional on the values of $y$ observed through date $t$. It is also possible to calculate smooth probabilities, $\mathrm{p}\left(\mathrm{s}_{\mathrm{t}} \mid \mathrm{y}_{\mathrm{T}}, \mathrm{y}_{\mathrm{T}-1}, \ldots, \mathrm{y}_{-3}\right)$, which are based on the full sample. The smooth probabilities give us $\mathrm{K}$ numbers for each date $\mathrm{t}$.

In this paper, we find that some autoregressive terms in the $\mathrm{SWARCH}(\mathrm{K}, \mathrm{q})-\mathrm{L}$ model hit the nonnegative boundary. This is mainly due to the presence of a strong leverage effect that drives the ARCH(1) coefficient, 1, to zero. Thus, we favor the E-SWARCH model, which does not require nonnegativity constraints. 


\section{SWITCHING VOLATILITY IN INTERNATIONAL STOCK MARKETS}

\section{A.- A Model of Stock Market Volatility}

In this section, we present a model of asset returns and conditional volatility for eight series of international stock returns. We use the model developed in Section II for the conditional variance process. Then, we briefly discuss the estimation aspects of the SWARCH model.

The model for stock returns, $\mathrm{r}_{\mathrm{t}}$, is a simple $\mathrm{AR}(1)$ process:

(6) $\mathrm{r}_{\mathrm{t}}=a+b \mathrm{r}_{\mathrm{t}-1}+\mathrm{e}_{\mathrm{t}}, \quad \mathrm{e}_{\mathrm{t}} \mid \Psi_{\mathrm{t}-1} \sim \mathrm{D}\left(0, \mathrm{~h}_{\mathrm{t}}\right)$,

(7) $\ln \left(h_{t}\right)=\ln \gamma_{s_{t}}+\alpha_{0}+\sum_{i=1}^{q} \alpha_{i} \frac{\left|e_{t-i}\right|}{\gamma_{s_{t-i}}}+\varepsilon \frac{e_{t-1}}{\gamma_{s_{t-1}}}$,

where $s_{t}$ describes the state of the economy and its evolution is given by the Markov matrix P. In this model, we are implicitly assuming that the conditional mean does not depend on $\mathrm{s}_{\mathrm{t}}$. This assumption simplifies the estimation and allows us to focus solely on time-variation in the conditional variance process. The AR(1) component allows for autocorrelation induced by nonsynchronous trading in the stocks making up the index, as suggested by Lo and MacKinlay (1990). GARCH models have been estimated using as conditional distributions the normal, Student-t, and the GED. The empirical literature tends to find that the Student-t distribution does a better job at describing the fat tails of the conditional errors. Therefore, we use as D the normal distribution and the Student-t distribution.

In general $\operatorname{GARCH}(\mathrm{q}, \mathrm{p})$ applications, a $\operatorname{GARCH}(1,1)$ model seems to be sufficient to capture the symmetric dynamics of the variance. The $\operatorname{GARCH}(1,1)$ has an implicit infinite lag, which cannot be generated in a SWARCH model. However, using an autoregressive model for squared residuals, Schwert (1990) employs an AR(12) with monthly variables. Computational constraints force us to use a shorter lag structure. Hamilton and Susmel (1994) use a model with two lags. We estimate different models, with different lags. We find that, in general, only the first two terms are needed to capture the ARCH effect. In only two cases a third autoregressive term seemed to be necessary on the conditional variance equation. 
Therefore, equation (7) is restricted to an $\operatorname{E-SWARCH}(\mathrm{K}, 3)$ process, which will also reduce computations. $^{2}$ Again, note that the E-SWARCH(K,q) model does not nest an E-GARCH(p,q) model. Although an $\mathrm{ARCH}(\mathrm{q})$ model can be seen as a special case of a $\mathrm{SWARCH}(\mathrm{K}, \mathrm{q})$ model, a likelihood ratio test is not an appropriate test. The usual regularity conditions do not hold, since the $\mathrm{p}_{\mathrm{ij}}$ 's are not identified under the null hypothesis that the $\mathrm{ARCH}$ parameters are constant across states. we take these likelihood ratio tests only as a quick check of the model.

We estimate different $\operatorname{SWARCH}(\mathrm{K}, \mathrm{q})$ specifications. We estimate models with $\mathrm{K}=2$ to $\mathrm{K}=3$ states and $\mathrm{q}=1$ to $\mathrm{q}=3$ autoregressive terms, and with and without leverage effects. We use Normal and Student$\mathrm{t}$ distributions for the conditional errors. We find that a leverage effect is significant on the conditional variance equation. As discussed before, in some series the presence of a strong leverage effect drives the $\operatorname{ARCH}(1)$ coefficient, $\quad$, to the boundary in the $\operatorname{SWARCH}(\mathrm{K}, \mathrm{q})-\mathrm{L}$ formulation. This is not a problem in the E-SWARCH $(\mathrm{K}, \mathrm{q})$ since there are no nonnegativity restrictions on the parameters. For both SWARCH specifications, however, the likelihood function, the mean, transition probabilities and switching parameters are of similar magnitude. Since the parameters are similar, the volatility states are also similar.

\section{B.- Empirical Results: GARCH and SWARCH models}

In our empirical application, we use weekly returns from six international stock markets and two international stock market indices compiled by Morgan Stanley Capital International Perspective. The six international markets considered are U.S., Canada, U.K., Germany, Japan and Australia. All trading time zones are represented in this sample. The market indices are the World Index and the EAFE (Europe, Australia and the Pacific) Index. The eight indices have been constructed so as not to double count those stocks multiple-listed on foreign stock exchanges. The indices are value weighted indexes and they cover at least $80 \%$ of each country's stock market capitalization. The sample covers the period from the first

2 In Table 6, we use the Ljung-Box statistic to test if there is further autocorrelation of 
week of January 1980 to the fourth week of July 1991. The last 25 observations are only used for out-ofsample forecasting. These stock market indices are transformed into weekly (Thursday to Thursday) rates of return. U.S. returns have a correlation of .80 with the S\&P 500. We should mention that each of these markets have different regulations, trading systems and transaction costs --see Roll (1988), for a summary of the characteristics of each market.

Table 1 provides univariate statistics for the six countries and two world indices in our sample. First order autocorrelations, Ljung-Box test statistics for serial correlation and ARCH tests are also calculated. The ARCH(4) tests are LM-type tests of the type described in Engle (1984). There is strong evidence for first order autocorrelation and ARCH effects in all markets except for the U.S. and the U.K. ${ }^{3}$

Table 2 reports the Gaussian E-GARCH(1,1) estimation. All series, with the exception of the U.K. and the U.S. markets show evidence of a positive first order autocorrelation, as expected from Table 1. There is evidence of ARCH effects on all the series except for the U.K. stock market. The leverage effect is negative and, in general, significant. We also report the log likelihood of the GARCH(1,1)-L model, LF-GJR. The likelihood functions LF and LF-GJR are extremely similar; however as noted before, some of the 1 's hit the nonnegativity restriction. We also report the likelihood of an E-GARCH(1,1) model estimated under the assumption of a t distribution for the conditional residuals, or E-GARCH-t estimation. There is strong evidence for the E-GARCH model with a t-distribution, which is consistent with previous studies (see Bollerslev (1987) and Baillie and DeGennaro (1990) for a non-switching specification and Hamilton and Susmel (1994) for a switching model).

Table 3 reports the E-SWARCH(2,2) estimation. First, note that a standard ARCH-L specification is obtained as a special case of the Markov-switching model by setting $\gamma_{2}=1$. The switching parameter, $\gamma_{2}$, is

the standardized squared residuals.

${ }^{3}$ The ARCH(4) tests for a linear relation between past and present squared residuals. Therefore, the $\mathrm{ARCH}(4)$ might not be able to detect asymmetric effects or non-linear relations, such as the one implied by the SWARCH model. 
significantly different than one at the 5\% level, with the exception of the World Index, the EAFE Index and the U.K. The lack of significance for the World Index, the EAFE Index and the U.K. is probably due to the fact that the high volatility state is composed of a few observations and dominated by the October 1987 crash. Thus, for these series, the estimate of $\gamma_{2}$ is imprecise. Australia presents the highest $\gamma_{2}$, this is due to the presence of two consecutive extraordinary observations in October 1987. On the other markets, volatility is three to six times bigger when the economy moves to the high volatility state. Second, Black's (1976) leverage effect is significant only for the World Index, the EAFE Index, the U.S. and Japan. Third, the ARCH effects, the 1's and 2 's, are reduced and, in general, they are non significant. Therefore, the usual ARCH effect seems to be driven by a switching constant and the leverage effect.

Table 3 also reports the likelihood of an $\operatorname{E-SWARCH}(2,2)$ model calculated under the assumption of a t-distribution, $\mathrm{LF}_{\mathrm{t}}$, and the likelihood of an $\mathrm{E}-\mathrm{SWARCH}(2,3)$ model, $\mathrm{LF}_{2,3}$. We take the Gaussian ESWARCH(2,2) model as the restricted model and perform a likelihood ratio test for the E-SWARCH(2,2)t model and the E-SWARCH(2,3) model. This likelihood ratio test follows a chi-squared distribution with one degree of freedom. Hamilton and Susmel (1994) find that for weekly CRSP returns, a conditional tdistribution significantly improves the likelihood function of the SWARCH model. Unlike the E-GARCH estimation, however, assuming a t-distribution for the conditional residuals does not result in a significantly higher likelihood than a normal distribution, with the marginal exception of Canada. That is, contrary to Hamilton and Susmel (1994), once switching in variance is allowed, the t-distribution does not help in explaining the fat tail distribution of conditional returns. Also, with the exception of the two market indexes, the E-SWARCH(2,3) is rejected in favor of the E-SWARCH(2,2) model. We tested for further autoregressive ARCH effects, using a Ljung-Box test, for the standardized square residuals, with six lags. This test statistic, $\operatorname{LBS}(6)$, is reported in Table 6. We do not find evidence of autocorrelation in the standardized squared residuals.

In Figures 1 to 6 we plot the weekly stock returns series for each country on the first panel and in the 
other panel the smoothed probabilities, $\operatorname{Prob}\left(\mathrm{s}_{\mathrm{t}}=1 \mid \mathrm{y}_{\mathrm{T}}, \mathrm{y}_{\mathrm{T}-1}, \ldots, \mathrm{y}_{-3}\right)$. The second panel plots the smoothed probability that the economy was at state 1 at time t. The smoothed probability that the economy was at state 2 at time $\mathrm{t}$ is the mirror image of the second panel. For brevity, we present figures for Canada, U.S., Germany, the U.K, Japan, and Australia. ${ }^{4}$ The dating of the states is not very revealing. At first glance, using the dating of the business cycles in Goodwin (1993), reported in Table 6, for Canada, the U.S., Germany, the U.K. and Japan, there does not seem to be any consistent relation between volatility regimes and business cycles. Similar conclusion can be drawn for the relation between volatility regimes and exchange rate regimes using the dates in Engel and Hamilton (1990) for the DM and the BP. Since we have weekly data for exchange rates, we test the relation between exchange rates and volatility regimes. We estimate the two-state model in Engel and Hamilton (1990) for weekly exchange rates and we date the exchange rate regimes for the CAD/USD, DM/USD, BP/USD, JPY/USD, AUD/USD and a tradeweighted USD rate. Then, using a Lagrange multiplier test, as described in Hamilton (1996), we test for the inclusion of an exchange regime dating dummy in the model for each national market. These LM-tests are reported in Table 6 (LM-ER). All the LM-tests cannot reject the null hypothesis of no-relation between volatility regimes and the regime for the local currency.

There are, however, two clear conclusions from Figures 1 to 6 . First, the economy tends to have longer stays in the low volatility state. ${ }^{5}$ The low volatility state has the longest expected duration. For example, the expected duration of the low volatility state in Canada and the U.S. is the same, 83 weeks. Also, note the extremely short duration of one state in the U.K., Australia and the EAFE (not shown), which indicates the impact of few observations in those states. Second, with the exception of Japan, the Crash of October 1987 was unexpected, in the sense that the market was in the low volatility state the

\footnotetext{
4 All graphs are available from the author, upon request.

${ }^{5}$ In Table 3 we report the expected duration of state $i$, given by $d_{i}=\left(1-p_{i i}\right)^{-1}$.
} 
week before the 1987 Crash. ${ }^{6}$ As pointed out by Engle and Mustafa (1992), Roll (1989) and Albert et al. (1993), among others, the Crash did not have long-lasting volatility implications. This is demonstrated in Figure 2, which corresponds to the U.S. Index. The 1987 Crash comes "unexpectedly" after the economy was for a long period in the low volatility state. Then, after eight weeks in the high volatility state, the economy reverts to the low volatility state.

As mentioned above, the second state in Figure 4 -corresponding to the U.K. market-, in Figure 6 Australia- and in the EAFE Figure (not shown) is dominated by the October 1987 Crash. This suggests that for these three markets a third state is necessary. Table 4 reports the results for the ESWARCH(3,2) estimation for the U.K., Australia and the EAFE Index. Under the null hypothesis of a ESWARCH $(2,2)$ model, the E-SWARCH $(3,2)$ has unidentified parameters. Thus, the usual asymptotic ${ }^{2}$ distribution for the likelihood ratio test does not hold. ${ }^{7}$ We can only take the small improvement of the likelihood function of the three state model as an indication that two states might be enough for the Markov-switching model. For dating volatility states, however, it might be useful to estimate a third state. In Figures 7 to 8 we plot the weekly returns along with the smooth probabilities for the first and second states for the U.K and Australia. The third state is dominated by the Crash of October 1987. For the U.K. and Australia, the picture is closer to the one presented by Japan, with long periods where the economy stays in the second state, the high volatility state. For these series, the predominant state is the high volatility state. These figures illustrate the effect of outliers on the estimation of the states. The

\footnotetext{
${ }^{6}$ Moreover, if we fit a SWARCH $(3,2)$ model to the Japanese data, the third state is composed by a single observation, a big positive return from the second half of 1985.

${ }^{7}$ When we test a SWARCH(K-1,q) model against a $\operatorname{SWARCH}(\mathrm{K}, \mathrm{q})$ model, standard likelihood tests are not valid. Under the null hypothesis of K-1 states, the parameters that describe the Kth state are not identified and therefore standard test statistics do not have the usual asymptotic distribution. Similar problems arise when test a SWARCH $(2, q)$ model against an $\operatorname{ARCH}(q)$ model, which could be described as a special case of a $\operatorname{SWARCH}(2, \mathrm{q})$ with $\mathrm{K}=1$, since under the null hypothesis the parameter $\gamma_{2}$ is not identified (see Davies (1977) or Hamilton (1996) for tests that get around this problem). We take the pvalues as a raw approximation.
} 
SWARCH $(3,2)$ formulation assigns a special state for these extraordinary observations and therefore this state acts as an intervention variable -in this case a pulse variable, since the 'intervention' takes place at only one point in time- defined by Box and Tiao (1975). In the cases where a few observations dominate the third state, it is possible to obtain a description of the volatility states using a $\operatorname{SWARCH}(2,2)$ model. We illustrate this procedure for Australia and the U.K. Since the third state seems to play the role of a dummy variable, we estimate an E-SWARCH(2,2) model with dummy variables for the observations that belong to the third state. For the U.K. market, those dates are the first week of October 1981, $t=90$, and the third week of October $1987, \mathrm{t}=407$. This is a pure pulse variable, the impact only affects the observation at those dates. For the Australian market, the dummy variables cover the third week and the four week of October $1987, \mathrm{t}=407$ and $\mathrm{t}=408$. These are also pure pulse variables. ${ }^{8}$ The results are reported in Table 5. The parameters are similar to the relevant first and second state parameters for the E-SWARCH $(3,2)$ model. The switching parameter for the second state is of the same magnitude as the switching parameter for the second state under the E-SWARCH $(3,2)$ model. Also the estimated smoothed probabilities (not shown) show the low and high volatility states are also similar to those estimated under an E-SWARCH(3,2) model.

The evidence from Figures 1 to 8, supports the survey of Roll (1989), with respect to the short-lived effects of the Crash of October 1987. By January 1988, two months after the Crash, all the markets seem to be in the low volatility state.

From Table 2, Table 3, and Table 4, we can point out some in-sample E-SWARCH results. In terms of the likelihood function, the Gaussian E-SWARCH model fits the data substantially better than the Gaussian E-GARCH formulation, even though, the E-GARCH formulation allows for more dynamics. The better fit of the E-GARCH(1,1)-t model suggests that the gains from the Switching ARCH model are not

${ }^{8} \mathrm{We}$ also use for the Australian case one dummy variable, an intervention step function which lasts two periods, that is, under this formulation the Crash of October 1987 only lasted two weeks. However, the states are better described with two intervention dummies. 
that significant and come more from capturing better the fat tails of the unconditional distribution than from capturing the autoregressive dynamics of the conditional variance.

A more rigorous test of the null hypothesis of no regime-switching can be done by using the likelihood ratio test proposed by Hansen $(1992,1994)$. As noted earlier, a likelihood ratio test of this null hypothesis does not have the usual limiting chi-squared distribution, because the parameters $\mathrm{p}_{\mathrm{ij}}$ are unidentified under the null. Hansen proposes a test, based on empirical theory process, that is able to provide an upper bound to the asymptotic distribution of standardized likelihood ratio statistics, even when conventional regularity conditions (such as unidentified parameters) are violated. ${ }^{9}$ We calculate Hansen's test for all the series under the null hypothesis of no regime-switching with a Student-t distribution. The p-values for the Hansen test are reported in Table 6. Consistent with Hamilton and Lin (1996) the null hypothesis of no regime switching can be rejected at the 5\% level for the U.S. For Canada and the U.K the null hypothesis is also rejected at the $5 \%$ level, while Japan seems to be a borderline case -recall that the Hansen tests provides an upper bound for the p-value. For the other series, the null hypothesis of no-regime switching cannot be rejected at the $5 \%$ level.

Our next comparison between the GARCH-t and SWARCH models is based on variance forecasts. In Table 2, Table 3 and Table 4, we report mean squared errors for the in-sample one step ahead variance forecasts, MSE(1). In four cases the SWARCH model presents a lower MSE(1), and in the other four

${ }^{9}$ To get around the problem of no identified parameters under the null, Hansen (1994) defines a function $\mathrm{q}_{\mathrm{t}}(\zeta)=\mathrm{L}_{\mathrm{t}}[\zeta, \lambda(\zeta)]-\mathrm{L}_{\mathrm{t}}\left[\zeta_{0}, \lambda\left(\zeta_{0}\right)\right]$

where $\mathrm{L}_{\mathrm{t}}[\zeta, \lambda(\zeta)]$, represents the conditional log likelihood of the th observation when evaluated at $\zeta$ and $\lambda(\zeta)$. The parameters $\zeta$ and $\lambda$ represent a partition of the parameter space. For the two-state case $\zeta=\left(\mathrm{p}_{11}, \mathrm{p}_{22}, \gamma_{2}\right)$. Under the null hypothesis of no regime-switching $\zeta=\zeta_{0}=(1,0,1)$. We investigated a grid containing 345 possible parameters for $\zeta$ under the alternative hypothesis, with $\mathrm{Z}$ consisting of these 345 possibilities considered. For any $\zeta, \lambda(\zeta)$ is estimated by maximizing the likelihood with respect to $\lambda$, given $\zeta$. Hansen (1994) proposes the following standardized test:

$$
\mathrm{LR}=\max _{\zeta \varepsilon Z} \mathrm{~T} \mathrm{mq}(\zeta) /\left[\Sigma_{\mathrm{t}}\left(\mathrm{q}_{\mathrm{t}}(\zeta)-\operatorname{mq}(\zeta)\right)^{2}\right]^{1 / 2},
$$

where $\mathrm{mq}$ is the mean of $\mathrm{q}_{\mathrm{t}}$. Hansen shows that, if the null hypothesis of no regime-change is true, then for large samples the probability that LR would exceed a critical value $\mathrm{z}$ is less than the probability that a Monte Carlo simulated statistic would exceed the same value $\mathrm{z}$. 
cases the GARCH-t model has a lower MSE(1). In Table 6, we compare both models in terms of out-ofsample variance forecasts. We report the square error for one week, four weeks, twelve weeks, and twenty-four weeks ahead variance forecasts. The results are mixed, however, the GARCH-t model tends to have lower squared variance forecasting errors than the SWARCH model. Out of thirty-two comparisons, the GARCH-t model outperforms the SWARCH model twenty-one times. These results are consistent with the findings of Goodwin (1993). In a different context, he finds that the Hamilton (1989) switching specification does not strongly dominate linear AR representations of GNP growth.

As shown in Hamilton (1989) and pointed out by Goodwin (1993), the most innovative aspect of the Hamilton (1989) model is the ability to date states. In the next section, we will take this observation into account. Then, we will analyze and compare the volatility states across the six international markets.

\section{C.- Dependent States}

As discussed in the introduction, one common finding of ARCH studies is the high persistence of shocks to the conditional variance. Bollerslev and Engle (1994) discuss the idea of common persistence. If two series exhibit co-persistence, a non-trivial linear combination will have no persistence in variance. Ghose and Kroner (1993) discuss the implications of common persistence for investors. Another related idea is common volatility, explored by Engle and Susmel (1993). In this section, we extend this idea of common volatility to volatility states. As pointed out by Roll (1992), world markets seem to react similarly to big common news. This common reaction might be a reflection of the contagion effect, discussed by King and Wadhwani (1990), where big mistakes are transmitted from one market to others. King and Wadhwani (1990) argue that the contagion effect increases with stock market volatility. If we consider periods of high volatility as periods of high contagion, we should expect the high volatility states to be correlated. Hamao et al. (1990) find evidence of "volatility spillovers" among the U.S., Japan and the U.K. This finding seems to confirm a positive correlation of high variances in international stock markets. In this 
section, we take advantage of the dating abilities of the Hamilton (1989) filter to explore these ideas and test two related hypotheses: first, we test if the volatility states are independent, and second, if independence is rejected, we test if the volatility states are common states.

To test the above hypotheses, we estimate a multivariate formulation of the E-SWARCH model. In order to keep the number of parameters tractable, we are going to test the above hypotheses by only using two series at a time. That is, we estimate a bivariate E-SWARCH model.

Suppose we have two series, with two volatility states. In this bivariate formulation, the number of states is four. For instance, with the U.S. and Japan in a system, we have the following four primitive states, $\mathrm{s}_{\mathrm{t}}$ :

$\mathrm{S}_{\mathrm{t}}{ }^{*}=1$ : U.S. - Low volatility, Japan - Low volatility.

$\mathrm{s}_{\mathrm{t}}^{*}=2$ : U.S. - Low volatility, Japan - High volatility.

$\mathrm{s}_{\mathrm{t}}{ }^{*}=3$ : U.S. - High volatility, Japan - Low volatility.

$\mathrm{S}_{\mathrm{t}}{ }^{*}=4$ : U.S. - High volatility, Japan - High volatility.

The system can be written as:

$$
\mathbf{r}_{t}=\mathbf{A}+\mathbf{B} \mathbf{r}_{t-1}+\mathbf{e}_{\mathbf{t}}, \quad \mathbf{e}_{t} \mid \Psi_{t} \sim N\left(\tilde{O}, \mathbf{H}_{t_{s} t, s_{t-1}^{*}}^{*}\right)
$$

where $\mathbf{r}_{\mathrm{t}}=\left[\mathrm{r}_{\mathrm{t}}^{\mathrm{x}}, \mathrm{r}_{\mathrm{t}}^{\mathrm{y}}\right]$ is a $2 \mathrm{x} 1$ vector of returns, $\mathbf{e}_{\mathrm{t}}=\left[\mathrm{e}_{\mathrm{t}}^{\mathrm{x}}, \mathrm{e}_{\mathrm{t}}^{\mathrm{y}}\right]$ is a $2 \mathrm{x} 1$ vector of disturbances, which follow a bivariate normal distribution, with zero mean and a time varying conditional covariance matrix $\mathbf{H}_{\mathrm{t}}$ (for notational convenience, we drop the dependence of $\mathbf{H}_{\mathrm{t}}$ on the states of the economy). The conditional covariance matrix $\mathrm{H}_{t}$ is specified as a diagonal matrix where the diagonal elements follow an E-SWARCH process. This specification allows the series $\mathrm{r}^{\mathrm{x}}{ }_{\mathrm{t}}$ and $\mathrm{r}_{\mathrm{t}}^{\mathrm{y}}$ to be related through the nonlinearities associated with dependent states. $\mathbf{A}=\left[\mathrm{a}_{\mathrm{x}}, \mathrm{a}_{\mathrm{y}}\right]$ and $\mathbf{B}=\left[\mathrm{b}_{\mathrm{x}}, \mathrm{b}_{\mathrm{y}}\right]$ are $2 \mathrm{x} 1$ vectors.

The probability law that causes the economy to switch among states is given by a $\mathrm{K}^{*}=4$ state Markov chain, $\mathrm{P}^{*}$, with a typical element given by $\operatorname{Prob}\left(\mathrm{s}_{\mathrm{t}}{ }^{*}=\mathrm{j} \mid \mathrm{s}_{\mathrm{t}-1} *=\mathrm{i}\right)=\mathrm{p}_{\mathrm{ij}}{ }^{*}$. For the four state model, some of 
the $\mathrm{p}_{\mathrm{ij}}{ }^{*}$ are close to zero, in order to get convergence, we treat these parameters as given and equal to zero. This reduces the number of parameters to be estimated.

As discussed in Hamilton and Lin (1996), this specification is very general and encompasses different interactions among the volatility states of both countries. That is, the transition probabilities, the $\mathrm{p}_{\mathrm{ij}}{ }^{*} \mathrm{~s}$, could be restricted to fit different assumptions about the underlying volatility states. For example, focusing on $\mathrm{p}_{24}{ }^{*}$, if the volatility states of the U.S and Japan are independent, then, $\mathrm{p}_{24} *=\mathrm{p}_{12}{ }^{\mathrm{US}} \mathrm{p}_{22}{ }^{\mathrm{JAP}}$. On the other hand, if the U.S. volatility states are shared by Japan, then $\mathrm{p}_{24} *=0$.

To test the null hypothesis of independent states, we first estimate a bivariate E-SWARCH model, imposing no restriction on the matrix $\mathrm{P}^{*}$. The log likelihood function of the unrestricted model is denoted as $\mathrm{LF}\left(\mathrm{H}_{\mathrm{A}}\right)$. We also estimate the model by imposing the restricted transition probability matrix, $\mathrm{P}^{*}$, with elements such as $p_{14}{ }^{*}=p_{12}{ }^{x} p_{12}{ }^{y}$. From this estimation, we keep the log likelihood function of the restricted model, $\mathrm{LF}\left(\mathrm{H}_{0}\right)$. Then, we calculate a Likelihood Ratio test, $\mathrm{LR}=-2 *\left(\mathrm{LF}\left(\mathrm{H}_{0}\right)-\mathrm{LF}\left(\mathrm{H}_{\mathrm{A}}\right)\right)$. Under the null hypothesis, this test has a $\chi^{2}$ distribution, with $\mathrm{k}$ degrees of freedom, where $\mathrm{k}$ is given by the number of additional parameters estimated under the alternative hypothesis. A similar procedure is used to test the hypothesis of common volatility states.

Note that unlike the other markets, the volatility states for the U.K. market and the Australian market are better dated by a SWARCH $(3, \mathrm{~K})$ model. We avoid joint estimation of different $\mathrm{SWARCH}(\mathrm{K}, 2)$ by reducing the estimation to a SWARCH(2,2) problem, for the U.K. and Australia. For these two markets, we use an E-SWARCH(2,2) model with mean dummies, as we do in Table 5. Based on the estimates of Tables 3 and 5, we impose the independent states constraint and we jointly estimate the system, given by (8). We estimate the bivariate E-SWARCH system for 6 pairs of series. For the first three pairs, we fit the bivariate model for the three biggest stock markets in the world: the U.S., Japan and the U.K. These markets may provide information about a common world volatility state. Then, for the second three pairs, we look at the regional markets. Table 8 presents the results of the bivariate estimation. The null 
hypothesis of independent volatility states cannot be rejected, with the exception of Japan and the U.K., and the U.S. and Canada. Note that these four series are the same series where the Hansen test rejected the no regime-switching null hypothesis.

For the two cases where we reject the hypothesis of independent states, that is, Japan and the U.K., and the U.S. and Canada, we test the null hypothesis of common volatility states. Under this hypothesis, every time the domestic economy is in the high (low) volatility state, the foreign economy is also in the high (low) volatility state. Under this hypothesis, we restrict the transition probability matrix, $\mathrm{P}^{*}$. For example, $\mathrm{p}_{13} *=\mathrm{p}_{23} *=\mathrm{p}_{33} *=\mathrm{p}_{34} *=0$. Therefore, under the common states hypothesis the sum of the i $\mathrm{p}_{\mathrm{ij}} *=0$ for $\mathrm{j}=2,3$. Under the unrestricted hypothesis these sums should be equal to one. We should note that the unrestricted model, with no restrictions on $\mathrm{P}^{*}$, and the restricted model are not entirely nested. For the bivariate system with Japan and the U.K., the restricted model has a likelihood function of -2489.1 , with 16 estimated parameters. That is, we observe only a moderate decrease of the restricted likelihood, with five less estimated parameters. We take this as evidence of common volatility states between Japan and the U.K.

We follow the above procedure for the case of the U.S. and Canada. We estimate the common volatility states bivariate E-SWARCH model. The restricted model has a likelihood function of -2262.2, with 16 estimated parameters. That is, there is a marginal improvement of the likelihood function under this more restrictive model, which we take as an indication of common volatility states. This finding supports the results of Mittoo (1992), where he reports that post-1981 the Canadian and the U.S. stock markets are integrated.

\section{CONCLUSIONS}

This paper applies a switching ARCH model to weekly returns from international stock markets. We use an exponential SWARCH, or E-SWARCH, which provides a state-dependent description of the 
behavior of the conditional variance. We find evidence of switching volatility for Canada, the U.S., the U.K., and Japan. Under the SWARCH model, we find that pure ARCH effects are significantly reduced when switching is allowed. Moreover, the ARCH dynamics seem to be driven by a switching constant and a leverage effect. We find that once switching is allowed, a t-distribution does not help to explain the fat tails of the conditional errors. We also find that the out-of-sample variance forecasts of the GARCH-t model tend to be superior to the SWARCH variance forecasts.

We analyze the dating of volatility states provided by the SWARCH model. Only around the Crash of October 1987, do international markets seem to be in the same volatility state. The effects of the Crash were short-lived; two months after the Crash all markets had returned to the low volatility state. Finally, we find that domestic volatility states tend to be independent of foreign volatility states. The exceptions are Japan and the U.K., and the U.S. and Canada. For these two pairs of markets, we find evidence for common volatility states. 
TABLE 1. UNIVARIATE STATISTICS

$\begin{array}{lllllllc}\text { MARKET } & \text { MEAN } & \text { SD } & \text { SKEW } & \text { EK } & \text { RHO } & \text { LB(6) } & \text { ARCH(4) } \\ & & & & & & & \\ \text { CANADA } & .15 & 2.64 & -0.76 & 5.53 & .16 & 29.43^{*} & 21.24^{*} \\ \text { US } & .22 & 2.25 & -1.03 & 8.04 & .05 & 12.68^{*} & 7.25 \\ \text { GERMANY } & .24 & 2.81 & -0.18 & 1.89 & .14 & 14.65^{*} & 39.88^{*} \\ \text { UK } & .25 & 3.03 & -1.07 & 7.29 & .00 & 9.32 & .52 \\ \text { JAPAN } & .46 & 2.73 & 0.05 & 0.94 & .10 & 9.02 & 16.06^{*} \\ \text { AUSTRALIA } & .16 & 3.70 & -2.07 & 15.55 & .18 & 25.95^{*} & 157.47^{*} \\ \text { WORLD } & .28 & 1.91 & -1.09 & 8.36 & .12 & 10.88^{*} & 14.51^{*} \\ \text { EAFE } & .34 & 2.18 & -0.54 & 3.67 & .13 & 12.34^{*} & 31.08^{*}\end{array}$

Notes:

* significant at the 5\% level.

EK: Excess kurtosis coefficient.

RHO: First order autocorrelation coefficient.

LB(6): Ljung-Box statistic with 6 lags.

$\mathrm{ARCH}(4)$ : $\mathrm{ARCH}$ test with 4 lags for the own squared returns. 
TABLE 2. E-GARCH(1,1) ESTIMATION

$$
\begin{aligned}
& \mathrm{r}_{\mathrm{t}}=a+b \mathrm{r}_{\mathrm{t}-1}+\mathrm{e}_{\mathrm{t}}, \quad \mathrm{e}_{\mathrm{t}} \mid \Psi_{\mathrm{t}-1} \sim \mathrm{D}\left(0, \mathrm{~h}_{\mathrm{t}}\right) \\
& \left.\ln \left(h_{t}\right)=\alpha_{0}+\beta_{1} \log \left(h_{t-1}\right)+\varepsilon \frac{e_{t-1}}{\sqrt{h_{t-1}}}+\alpha_{l}\left(\frac{\left|e_{t-1}\right|}{\sqrt{h_{t-1}}}-\sqrt{(} 2 / \pi\right)\right)
\end{aligned}
$$

\begin{tabular}{|c|c|c|c|c|c|c|c|c|}
\hline \multicolumn{3}{|c|}{ CANADA } & \multicolumn{2}{|l|}{ U.S. } & \multicolumn{2}{|c|}{ GERMANY } & \multicolumn{2}{|l|}{ U.K. } \\
\hline$a$ & .081 & $(.05)$ & .254 & (.09) & .253 & $(.12)$ & .154 & (.13) \\
\hline$b$ & .186 & (.04) & .073 & (.05) & .109 & (.04) & .026 & (.05) \\
\hline 0 & .184 & (.06) & .367 & (.17) & 2.062 & $(.77)$ & .154 & (.14) \\
\hline 1 & .290 & (.08) & .307 & (.07) & .384 & (.10) & .071 & (.04) \\
\hline ß1 & .893 & (.03) & .755 & (.11) & -.023 & (.38) & .932 & (.06) \\
\hline & -.166 & (.04) & -.175 & (.06) & -.057 & $(.07)$ & -.015 & (.04) \\
\hline \multicolumn{2}{|l|}{$\mathrm{L}:$} & 1174.5 & \multicolumn{2}{|c|}{1122.0} & \multicolumn{2}{|c|}{1255.4} & \multicolumn{2}{|c|}{1307.3} \\
\hline \multicolumn{2}{|l|}{$\mathrm{L}_{\mathrm{t}}$ : } & 1161.0 & \multicolumn{2}{|c|}{1115.1} & \multicolumn{2}{|c|}{1250.5} & \multicolumn{2}{|c|}{1283.1} \\
\hline \multicolumn{2}{|c|}{$\mathrm{v}:$} & $8.1(2.65)$ & & 9.7 (2.29) & \multicolumn{2}{|c|}{$7.8(2.12)$} & \multicolumn{2}{|c|}{$7.9(2.03)$} \\
\hline \multicolumn{2}{|c|}{ L-GJR: } & 1175.8 & \multicolumn{2}{|c|}{1116.2} & \multicolumn{2}{|c|}{1256.0} & \multicolumn{2}{|c|}{1307.5} \\
\hline \multicolumn{2}{|c|}{$\operatorname{MSE}(1):$} & 293.4 & \multicolumn{2}{|c|}{243.4} & \multicolumn{2}{|c|}{201.9} & \multicolumn{2}{|c|}{775.2} \\
\hline \multicolumn{3}{|c|}{ JAPAN } & \multicolumn{2}{|c|}{ AUSTRALIA } & \multicolumn{2}{|c|}{ WORLD } & \multicolumn{2}{|c|}{ EAFE } \\
\hline$a$ & .390 & $(.12)$ & .170 & $(.15)$ & .199 & (.09) & .257 & (.09) \\
\hline$b$ & .108 & (.05) & .107 & $(.05)$ & .141 & $(.05)$ & .166 & (.05) \\
\hline 0 & .299 & (.12) & .894 & $(.28)$ & .513 & (.14) & .380 & (.17) \\
\hline 1 & .222 & (.06) & .150 & $(.07)$ & .222 & (.10) & .164 & (.06) \\
\hline \multirow[t]{2}{*}{ ß1 } & .850 & (.06) & .640 & (.11) & .577 & (.12) & .752 & (.11) \\
\hline & -.067 & (.03) & -.197 & (.06) & -.328 & (.06) & -.127 & (.05) \\
\hline \multicolumn{2}{|c|}{ LF: } & 1237.1 & \multicolumn{2}{|c|}{1375.0} & \multicolumn{2}{|c|}{1041.6} & \multicolumn{2}{|c|}{1122.4} \\
\hline \multirow{2}{*}{\multicolumn{2}{|c|}{$\begin{array}{l}\mathrm{LF}_{\mathrm{t}} \text { : } \\
\mathrm{v}\end{array}$}} & 1232.0 & & 48.2 & & 25.2 & & 55.0 \\
\hline & & $11.3(2.07)$ & & $6.1(2.79)$ & & $8.7(2.66)$ & & 8.7 (2.69) \\
\hline $\mathrm{LF}$ & GJR: & 1236.3 & & 78.5 & & +2.4 & & 21.1 \\
\hline MS & $E(1):$ & 152.2 & & 39.6 & & 29.7 & & 17.3 \\
\hline
\end{tabular}

Notes:

Standard errors in parenthesis.

LF: negative log likelihood for the E-GARCH(1,1) model.

$\mathrm{LF}_{\mathrm{t}}$ : negative log likelihood when a student-t distribution for the conditional residuals.

$\mathrm{v}$ : degrees of freedom of the t-distribution.

LF-GJR: negative log likelihood for the GARCH(1,1)-L.

MSE(1): Mean square error for the one-step ahead in-sample variance forecast for E-GARCH(1,1)-t. 
TABLE 3. SWARCH(2,2) ESTIMATION

$$
\begin{aligned}
& \mathrm{r}_{\mathrm{t}}=a+b \mathrm{r}_{\mathrm{t}-1}+\mathrm{e}_{\mathrm{t}}, \quad \mathrm{e}_{\mathrm{t}} \mid \Psi_{\mathrm{t}-1} \sim \mathrm{D}\left(0, \mathrm{~h}_{\mathrm{t}}\right) \\
& \ln \left(h_{t}\right)=\ln \gamma_{s_{t}}+\boldsymbol{\alpha}_{0}+\sum_{i=1}^{q=2} \boldsymbol{\alpha}_{i} \frac{\left|e_{t-i}\right|}{\gamma_{s_{t-i}}}+\varepsilon \frac{e_{t-1}}{\gamma_{s_{t-1}}} .
\end{aligned}
$$

\begin{tabular}{|c|c|c|c|c|c|c|c|c|}
\hline \multicolumn{3}{|c|}{ CANADA } & \multicolumn{2}{|c|}{ U.S. } & \multicolumn{2}{|c|}{ GERMANY } & \multirow{2}{*}{\multicolumn{2}{|c|}{$\begin{array}{l}\text { U.K. } \\
.285\end{array}$}} \\
\hline$a$ & . 164 & (.09) & .216 & $(.09)$ & .179 & (.12) & & $(.13$ \\
\hline$b$ & .160 & $(.05)$ & .020 & $(.05)$ & .113 & $(.05)$ & -.001 & \\
\hline $\mathrm{p}_{11}$ & .988 & & .988 & & .957 & & .986 & \\
\hline $\mathrm{p}_{22}$ & .971 & & .870 & & .874 & & .001 & \\
\hline 0 & .805 & (.17) & 1.107 & (.18) & 1.557 & $(.20)$ & 1.848 & \\
\hline 1 & .099 & (.09) & .087 & (.08) & .058 & (.09) & .043 & \\
\hline 2 & .156 & (.08) & -.013 & (.07) & -.034 & (.07) & .029 & \\
\hline & .005 & $(.05)$ & -.113 & (.04) & -.052 & (.04) & .016 & \\
\hline$\gamma_{2}$ & 5.652 & (1.08) & 6.020 & (1.88) & 3.181 & (.74) & 18.47 & (13.5 \\
\hline LF & & 1167.6 & 110 & & & 8.9 & & 128 \\
\hline LF & & 1165.7 & 110 & & & 8.9 & & 127 \\
\hline LF & & 1167.6 & $110^{\circ}$ & & & 8.7 & & \\
\hline LF & & 1164.1 & 110 & & & 7.5 & & 127 \\
\hline$d_{1}$ : & & 83.3 & & & & 3.3 & & \\
\hline $\mathrm{d}_{2}$ : & & 34.5 & & & & 7.9 & & \\
\hline & $\mathrm{E}(1):$ & 306.8 & 241 & & 199 & & & 781. \\
\hline
\end{tabular}

\begin{tabular}{|c|c|c|c|c|c|c|c|c|}
\hline \multicolumn{3}{|c|}{ JAPAN } & \multicolumn{2}{|c|}{ AUSTRALIA } & \multicolumn{2}{|c|}{ WORLD } & \multicolumn{2}{|c|}{ EAFE } \\
\hline$a$ & .348 & $(.12)$ & .391 & $(.12)$ & .259 & $(.08)$ & .333 & (.09) \\
\hline$b$ & .110 & $(.05)$ & .053 & $(.04)$ & .113 & $(.05)$ & .137 & $(.05)$ \\
\hline $\mathrm{p}_{11}$ & .979 & & .162 & & .990 & & .990 & \\
\hline $\mathrm{p}_{22}$ & .968 & & .919 & & .864 & & .634 & \\
\hline 0 & 1.313 & (.19) & -.524 & (.35) & .806 & (.16) & 1.018 & (.13) \\
\hline 1 & .068 & $(.08)$ & 1.176 & (.38) & .080 & $(.07)$ & .095 & $(.06)$ \\
\hline 2 & -.005 & $(.10)$ & .120 & $(.22)$ & .034 & $(.08)$ & 107 & $(.06)$ \\
\hline & -.086 & $(.04)$ & -.142 & $(.18)$ & -.142 & $(.05)$ & -.074 & $(.03)$ \\
\hline$\gamma_{2}$ & 3.049 & $(.52)$ & 13.26 & (4.47) & 5.933 & (3.08) & 9.650 & (6.71) \\
\hline LF & & 1231.0 & & 1346.7 & & 026.6 & & 1107.7 \\
\hline LF & & 1230.9 & & 1346.1 & & 025.9 & & 1107.6 \\
\hline LF & & 1229.6 & & 1346.1 & & 024.7 & & 1105.6 \\
\hline LF & & 1229.5 & & 1342.1 & & 022.3 & & 1103.4 \\
\hline$d_{1}:$ & & 47.6 & & 1.2 & & 100.0 & & 100.0 \\
\hline $\mathrm{d}_{2}:$ & & 31.2 & & 12.3 & & 7.4 & & 2.7 \\
\hline & $\mathrm{E}(1):$ & 153.2 & & 2549.2 & & 126.7 & & 119.8 \\
\hline
\end{tabular}

Notes: Standard errors in parenthesis.

$\mathrm{LF}_{2,3}$ : E-SWARCH $(2,3)$ negative log likelihood. $\mathrm{LF}_{3,2}$ : E-SWARCH $(3,2)$ negative log likelihood. $\mathrm{d}_{\mathrm{i}}$ : duration of state $\mathrm{i}$. 
TABLE 4. SWARCH(3,2) ESTIMATION

\begin{tabular}{|c|c|c|c|c|c|c|}
\hline \multicolumn{3}{|c|}{ U.K. } & \multicolumn{2}{|c|}{ AUSTRALIA } & \multicolumn{2}{|c|}{ EAFE } \\
\hline$a$ & .289 & $(.15)$ & .275 & (.13) & .371 & $(.09)$ \\
\hline$b$ & .014 & (.44) & .055 & (.04) & .123 & $(.05)$ \\
\hline 0 & 1.403 & $(.29)$ & 1.575 & $(.29)$ & 1.259 & $(.16)$ \\
\hline 1 & .004 & (.16) & -.025 & $(.08)$ & .053 & $(.04)$ \\
\hline 2 & .007 & (.13) & -.098 & (.08) & .083 & $(.05)$ \\
\hline & .020 & $(.56)$ & -.003 & (.06) & -.061 & (.03) \\
\hline$\gamma_{2}$ & 2.244 & $(.78)$ & 2.726 & $(.56)$ & 3.181 & $(.14)$ \\
\hline$\gamma_{3}$ & 61.886 & (173.73) & 124.680 & (103.83) & 8.910 & $(5.78)$ \\
\hline LF & & 1277.6 & & 1342.1 & & 1103.4 \\
\hline $\mathrm{d}_{1}$ : & & 19.2 & & 16.5 & & 30.0 \\
\hline $\mathrm{d}_{2}$ : & & 32.4 & & 52.1 & & 17.7 \\
\hline $\mathrm{d}_{3}:$ & & 1.0 & & 2.0 & & 1.0 \\
\hline & $\mathrm{E}(1)$ & 780.7 & & 2574.5 & & 121.1 \\
\hline & (4) & 80.3 & & 124.7 & & 6.0 \\
\hline & (12) & 59.8 & & 126.6 & & 229.1 \\
\hline & (24) & 69.1 & & 94.0 & & 10.1 \\
\hline
\end{tabular}

Notes: See Table 3. 


\section{TABLE 5. SWARCH(2,2) ESTIMATION WITH INTERVENTION DUMMIES}

$$
\begin{aligned}
& \mathrm{r}_{\mathrm{t}}=a+b \mathrm{r}_{\mathrm{t}-1}+d \mathrm{I}_{\mathrm{t}}+\mathrm{e}_{\mathrm{t}}, \quad \mathrm{e}_{\mathrm{t}} \mid \Psi_{\mathrm{t}-1} \sim \mathrm{N}\left(0, \mathrm{~h}_{\mathrm{t}}\right) \\
& \ln \left(h_{t}\right)=\ln \gamma_{s_{t}}+\alpha_{0}+\sum_{i=l}^{q=2} \boldsymbol{\alpha}_{i} \frac{\left|e_{t-i}\right|}{\gamma_{s_{t-i}}}+\varepsilon \frac{e_{t-1}}{\gamma_{s_{t-1}}} .
\end{aligned}
$$

where $\mathrm{I}_{\mathrm{t}}$ is an intervention variable, $\mathrm{I}_{\mathrm{t}}=1$ if $\mathrm{t}=\mathrm{T}$ and zero otherwise. For the U.K. there are two intervention

\begin{tabular}{|c|c|c|c|c|}
\hline \multicolumn{3}{|c|}{ U.K. } & \multicolumn{2}{|c|}{ AUSTRALIA } \\
\hline$a$ & .297 & (.15) & .275 & (.13) \\
\hline$b$ & -.015 & (.44) & .051 & $(.04)$ \\
\hline$d 1$ & -23.902 & $(2.83)$ & -31.320 & (3.36) \\
\hline$d 2$ & -12.622 & (1.06) & -27.248 & $(3.55)$ \\
\hline 0 & 1.468 & $(.25)$ & 1.538 & $(.28)$ \\
\hline 1 & -.003 & $(.01)$ & -.022 & $(.08)$ \\
\hline 2 & -.004 & $(.01)$ & -.095 & $(.08)$ \\
\hline & .028 & $(.48)$ & -.001 & $(.05)$ \\
\hline$\gamma_{2}$ & 2.268 & $(.45)$ & 2.773 & $(.57)$ \\
\hline LF: & 1261.7 & & & 328.7 \\
\hline $\mathrm{d}_{1}:$ & 20.0 & & & 17.7 \\
\hline $\mathrm{d}_{2}:$ & 48.6 & & & 70.4 \\
\hline p-value: & 0.003 & & & 0.058 \\
\hline
\end{tabular}
dummies at $\mathrm{T}=90$ and $\mathrm{T}=407$. For Australia, there are two intervention dummies at $\mathrm{T}=407$ and $\mathrm{T}=408$.

Notes: See Table 3. 


\section{TABLE 6. BUSINESS CYCLE DATES AND SPECIFICATION TESTING}

\begin{tabular}{|c|c|c|c|c|}
\hline & CANADA & U.S. & GERMANY & U.K. \\
\hline Peak & & 1980:I & 1980:I & 1979:IV \\
\hline Through & & 1980:III & 1980:IV & 1980:III \\
\hline Peak & 1981:I & 1981:I & 1981:III & 1982:III \\
\hline Through & 1982:II & 1982:IV & 1983:II & 1982:IV \\
\hline Peak & & & & 1985:II \\
\hline Through & & & & 1988:III \\
\hline p-value: & 0.009 & 0.047 & 0.122 & 0.032 \\
\hline $\operatorname{LBS}(6)$ & 1.149 & 8.280 & 5.513 & 0.961 \\
\hline LM-ER & 0.049 & 0.951 & 1.460 & 2.450 \\
\hline
\end{tabular}

\section{JAPAN AUSTRALIA}

Through 1975:I N.A.

p-value: $\quad 0.055 \quad 0.140$

LBS(6): $\quad 0.997 \quad 2.514$

LM-ER: $\quad 2.157 \quad 0.339$

Notes:

Through and Peak dates are from a Markov-switching model for quarterly GNP, as reported by Goodwin (1993).

p-value: p-value of Markov Switching Hansen's (1992) test.

LM-ER: LM-test for inclusion of an exchange rate regime dating dummy variable.

LBS(6): Ljung-Box statistic for squared residuals, with six lags. 
TABLE 7. FORECASTING: SWARCH(2,2) and GARCH(1,1)-t

\begin{tabular}{lcccc} 
& \multicolumn{2}{c}{ CANADA } & U.S. \\
& GARCH & SWARCH & GARCH & SWARCH \\
SE(1) & $0.6 E-3$ & $3.1 E-6$ & 0.1 & 0.9 \\
SE(4) & 11.5 & 36.7 & 16.5 & 22.5 \\
SE(12) & 15.4 & 33.7 & 9.4 & 11.1 \\
SE(24) & 0.2 & 2.7 & 15.9 & 17.9
\end{tabular}

\begin{tabular}{lcccl} 
& \multicolumn{2}{c}{ GERMANY } & U.K. \\
& GARCH & SWARCH & GARCH & SWARCH \\
SE(1) & 136.5 & 102.4 & 9.6 & 12.1 \\
SE(4) & 17.0 & 21.1 & 65.0 & 83.7 \\
SE(12) & 40.8 & 39.9 & 50.7 & 62.9 \\
SE(24) & 159.8 & 170.0 & 60.7 & 73.1
\end{tabular}

\begin{tabular}{lcccc} 
& \multicolumn{2}{c}{ JAPAN } & \multicolumn{2}{c}{ AUSTRALIA } \\
& GARCH & SWARCH & GARCH & SWARCH \\
SE(1) & 33.8 & 37.6 & 102.5 & 93.9 \\
SE(4) & 30.9 & 39.1 & 104.8 & 132.7 \\
SE(12) & 647.2 & 498.3 & 112.8 & 131.6 \\
SE(24) & 2.3 & 0.3 & 75.6 & 94.2
\end{tabular}

\begin{tabular}{lcccc} 
& \multicolumn{2}{c}{ WORLD } & \multicolumn{2}{c}{ EAFE } \\
& GARCH & SWARCH & GARCH & SWARCH \\
SE(1) & 1.4 & 1.2 & 0.4 & 0.1 \\
SE(4) & 2.2 & 4.2 & 3.8 & 5.3 \\
SE(12) & 8.6 & 4.7 & 223.3 & 217.9 \\
SE(24) & 4.9 & 5.4 & 10.1 & 9.5
\end{tabular}

Notes:

SE(j): out-of-sample j-step ahead variance forecast squared error:

$$
S E(j)=\left[\hat{h}_{T+j}-\left(r_{T+j}-\hat{a}-\hat{b}_{r_{T+j-1}}\right)^{2}\right]^{2}
$$

where $\mathrm{T}=$ sample size. 


\section{TABLE 8. TEST FOR INDEPENDENT STATES}

A.- U.S. and U.K.

$\mathrm{LF}_{0}$ : -2370.5 (18)

$\mathrm{LF}_{\mathrm{A}}: \quad-2368.3(22)$

LR:4.4 (.35457)

B.- U.S. and Japan

$\mathrm{LF}_{0}: \quad-2339.8(16)$

$\mathrm{LF}_{\mathrm{A}}:-2336.5(21)$

LR:6.6 (.25213)

C.- Japan and U.K.

$\mathrm{LF}_{0}: \quad \quad-2493.0(18)$

$\mathrm{LF}_{\mathrm{A}}: \quad-2488.0(21)$

LR: $10.0(.018566)$

D.- U.S. and Canada

$\mathrm{LF}_{0}$ : -2278.5 (16)

$\mathrm{LF}_{\mathrm{A}}: \quad-2263.0(17)$

LR:30.1 (4.11E-08)

E.- U.K. and Germany

$\mathrm{LF}_{0}: \quad-2510.9$ (18)

$\mathrm{LF}_{\mathrm{A}}:-2505.9$ (23)

LR: $10.0(.075235)$

F.- Japan and Australia

$\mathrm{LF}_{0}: \quad-2560.7(17)$

$\mathrm{LF}_{\mathrm{A}}: \quad-2556.7(24)$

LR:8.0 (.33259)

Notes:

$\mathrm{LF}_{0}$ : Log Likelihood under the null hypothesis of independent volatility states. Number of parameters in parenthesis.

$\mathrm{LF}_{\mathrm{A}}$ : Log Likelihood of the unconstrained model. Number of parameters in parenthesis.

LR: Likelihood ratio test. p-values in parenthesis. 


\section{$\underline{\text { References }}$}

Albert , R.L, T.R. Smaby and S.B. Wyatt (1993), "Did Black Monday Have Permanent Effects?," Journal of Financial Research, 16, 123-138.

Baillie, R.T. and R.P. DeGennaro (1990), "Stock Returns and Volatility," Journal of Financial and Quantitative Analysis, 25, 203-214.

Black, F. (1976), "Studies of Stock Market Volatility Changes," Proceedings of the American Statistical Association, Business and Economics Statistics Section, 1976, 177-181.

Bollerslev, T.P. (1986), "Generalized Autoregressive Conditional Heteroscedasticity," Journal of Econometrics, 31, 309-328.

Bollerslev, T.P. (1987), "A Conditional Time Series Model for Speculative Prices and Rates of Returns," Review of Economics and Statistics, 69, 524-54.

Bollerslev, T.P., R.Y. Chou and K.F. Kroner (1992), "ARCH Modeling in Finance: A Review of the Theory and Empirical Evidence," Journal of Econometrics, 69, 542-547.

Bollerslev, T.P. and R.F. Engle (1994), "Common Persistence in Conditional Variances," Econometrica, 61, pp. 167-186.

Box, G.E.P and G.C. Tiao (1975), Intervention analysis with implications to economics and environmental problems, Journal of the American Statistical Association, 70, 70-79.

Brunner, A.D. (1991), "Testing for Structural Breaks in U.S. Post-war Inflation Data," mimeographed, Board of Governors of the Federal Reserve System, Washington D.C.

Cai, Jun (1994), "A Markov Model of Unconditional Variance in ARCH," Journal of Business and Economic Statistics, 12, 309-316.

Cho, D.C, C.S. Eun and L.W. Senbet (1986), " International Arbitrage Pricing Theory: An Empirical Investigation," Journal of Finance, 41, 313-329.

Christie, A.A. (1982), "The Stochastic Behavior of Common Stock Variances: Value, Leverage and Interest Rate Effects," Journal of Financial Economics, 10, 407-432.

Davies, R.B. (1977), "Hypothesis Testing When a Nuisance Parameter is Present Only under the Alternative," Biometrika, 64, 247-254.

Engel, C. and J.D. Hamilton (1990), "Long Swings in the Exchange Rate: Are They in the Data and Do Markets Know it?," American Economic Review, 80, 689-713.

Engle, R.F. (1982), "Autoregressive Conditional Heteroskedasticity with Estimates of the Variance of U.K," Econometrica, 50, 987-1008. 
Engle, R.F. (1984), "Wald, Likelihood Ratio, and Lagrange Multiplier Tests in Econometrics," in Z. Griliches and M.D. Intriligator (eds.), Handbook of Econometrics, Volume II. Elsevier Science Publishers.

Engle, R.F. and C. Mustafa (1992),"Implied ARCH Models from Options Prices," Journal of Econometrics, 52, 289-311.

Engle, R.F. and V.K. Ng (1993), "Measuring and Testing the impact of news on Volatility," Journal of Finance, 48, 1749-1778.

Engle, R.F. and R. Susmel (1993), "Common Volatility in International Equity Markets," Journal of Business and Economic Statistics, 11,2, 167-176.

Furstenberg, G.M. von and B.N. Jeon (1989), "International Stock Price Movements: Links and Messages," Brookings Papers on Economic Activity, I:1989.

Ghose, D. and K.F. Kroner (1993), "Common Persistence in Conditional Variances: Implications for Optimal Hedging," unpublished mimeograph, Department of Economics, University of Arizona.

Glosten, L.R., R. Jagannathan and D. Runkle (1993), "Relationship between the Expected Value and the Volatility of the Nominal Excess Return on Stocks," Journal of Finance, 48, 1779-1801.

Goodwin, T.H. (1993), "Business-Cycle Analysis with a Markov-Switching Model," Journal of Business and Economic Statistics, 11, 331-339.

Hall, S.G. and M. Sola (1996), "Structural Breaks and GARCH Modelling," in M. Gilli (ed), Computational Economic Systems, Models, Methods and Econometrics, Kluwer, The Netherlands.

Hamao, Y.R., R. Masulis and V. Ng (1990), "Correlations in Price Changes and Volatility across International Markets," Review of Financial Studies, 3, 281-307.

Hamilton, James D. (1989), "A New Approach to the Economic Analysis of Nonstationary Time Series and the Business Cycle," Econometrica, 57, 357-384.

Hamilton, James D. (1996), "Specification Testing in Markov-Switching Time Series Models," Journal of Econometrics, 70, 127-157.

Hamilton, James D. and G. Lin (1996), "Stock Market Volatility and the Business Cycle," Journal of Applied Econometrics, 11, 573-593.

Hamilton, James D. and R. Susmel (1994), "Autoregressive Conditional Heteroskedasticity and Changes in Regime," Journal of Econometrics, 64, 307-333.

Hansen, B.E. (1992), "The Likelihood Ratio Test under Non-standard Conditions: Testing the MArkov Trend Model of GNP," Journal of Applied Econometrics, 7, S61-S82. 
Hansen, B.E. (1994), "Erratum: The Likelihood Ratio Test under Non-standard Conditions: Testing the Markov Trend Model of GNP," working paper, Boston College.

King, M. and S. Wadhwani (1990), "Transmission of Volatility Between Stock Markets," The Review of Financial Studies, 3, 5-33.

Lamoreux, C.G. and W. D. Lastrapes (1990a), "Persistence in Variance, Structural Change and the GARCH Model," Journal of Business and Economic Statistics, 5, 121-129.

Lamoreux, C.G. and W. D. Lastrapes (1990b), 'Heteroskedasticity in Stock Return Data: Volume versus GARCH Effects," Journal of Finance, 45, 221-229.

Lo, A.W. and A.C. MacKinlay (1990), "An Econometric Analysis of Nonsynchronous Trading," Journal of Econometrics, 45, 181-211.

Mandelbrot, B.B. (1963), "The Variation of Certain Speculative Prices," Journal of Business, 36, 394-419.

Mittoo, U.R. (1992), "Additional Evidence on Integration in the Canadian Stock Market," Journal of Finance, 47, 2035-2054.

Nelson, D.B. (1991), "Conditional Heteroskedasticity in Asset Returns: A New Approach," Econometrica, 59, 347-370.

Roll, R. (1988), "The International Crash of October 1987," in R. Kamphuis, R. Kormendi and H Watson (eds.) Black Monday and the Future of Financial Markets. Irwin, Homewood, IL.

Roll, R. (1989), "Price Volatility, International Markets Links and their Implications for Regulatory Policies," Journal of Financial Services Research, 3, 211-246.

Roll, R. (1992), "Industrial Structure and the Comparative Behavior of International Stock Market Indexes," 47, 3-41.

Schwert, G.W. (1990), "Stock Volatility and the Crash of 87," Review of Financial Studies, 3, 77-102. 
Figure 1: Canada $\operatorname{SWARCH}(2,2)$
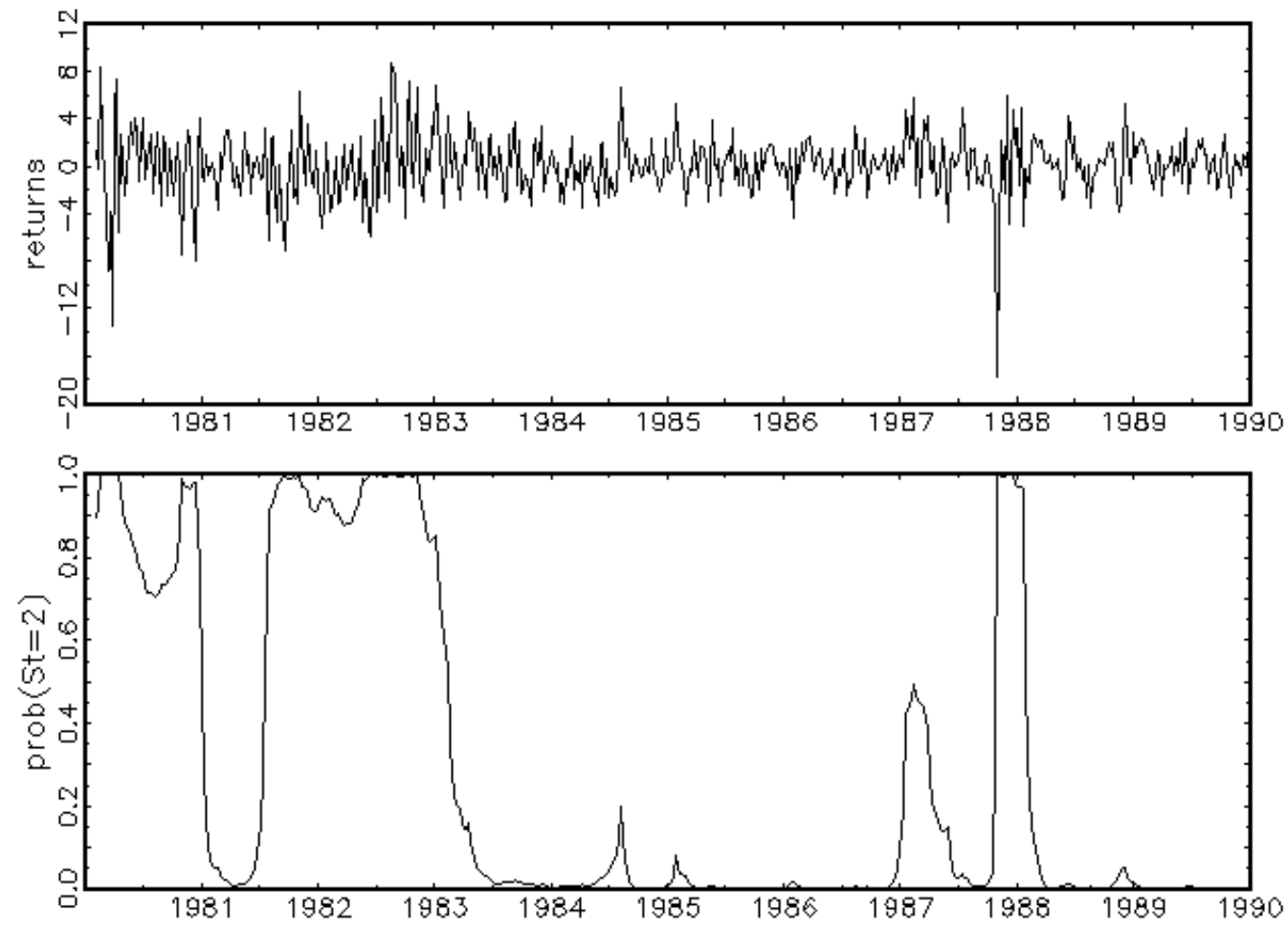
Figure 2: U.S. SWARCH(2,2)
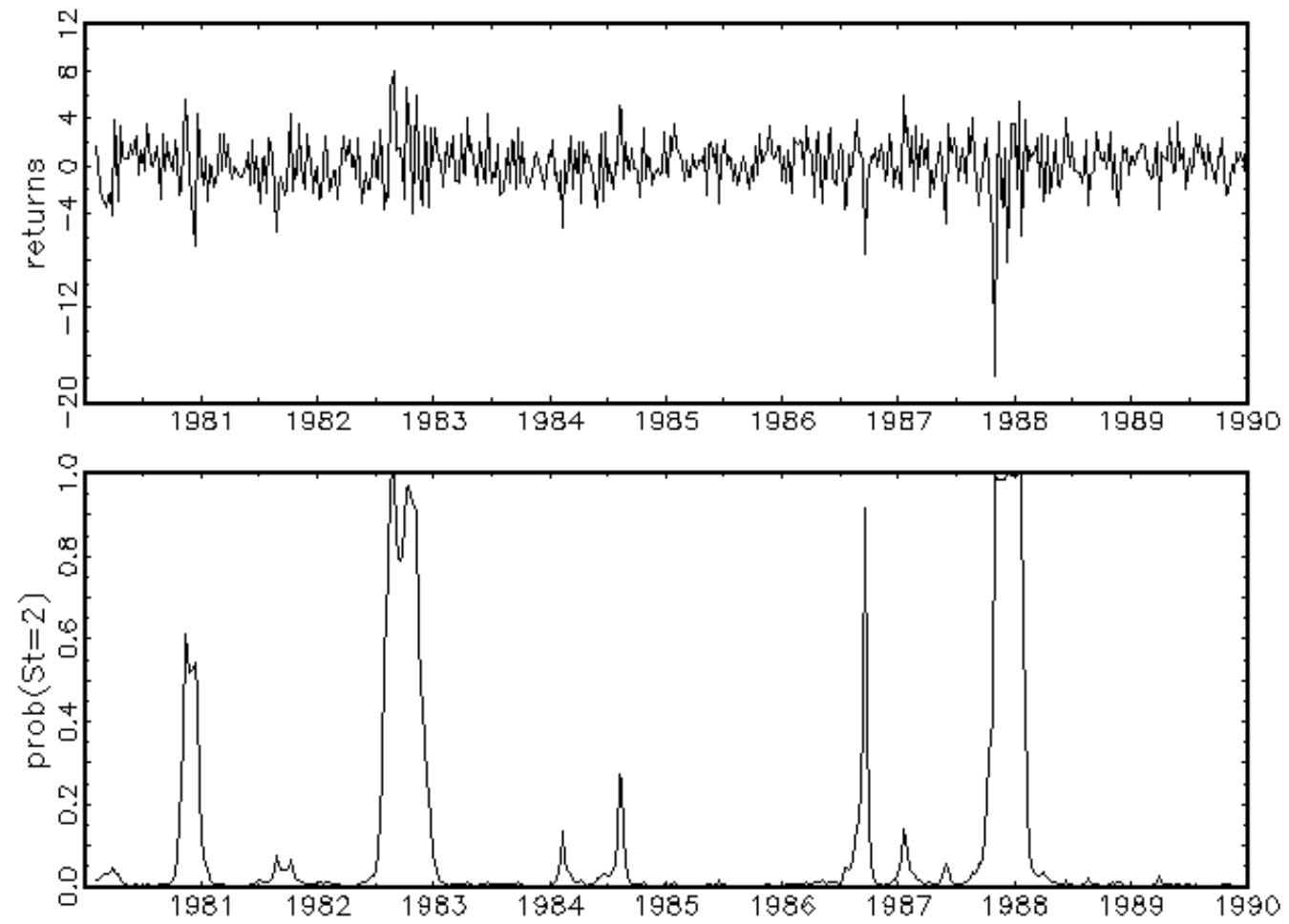
Figure 3: Germany $\operatorname{SWARCH}(2,2)$
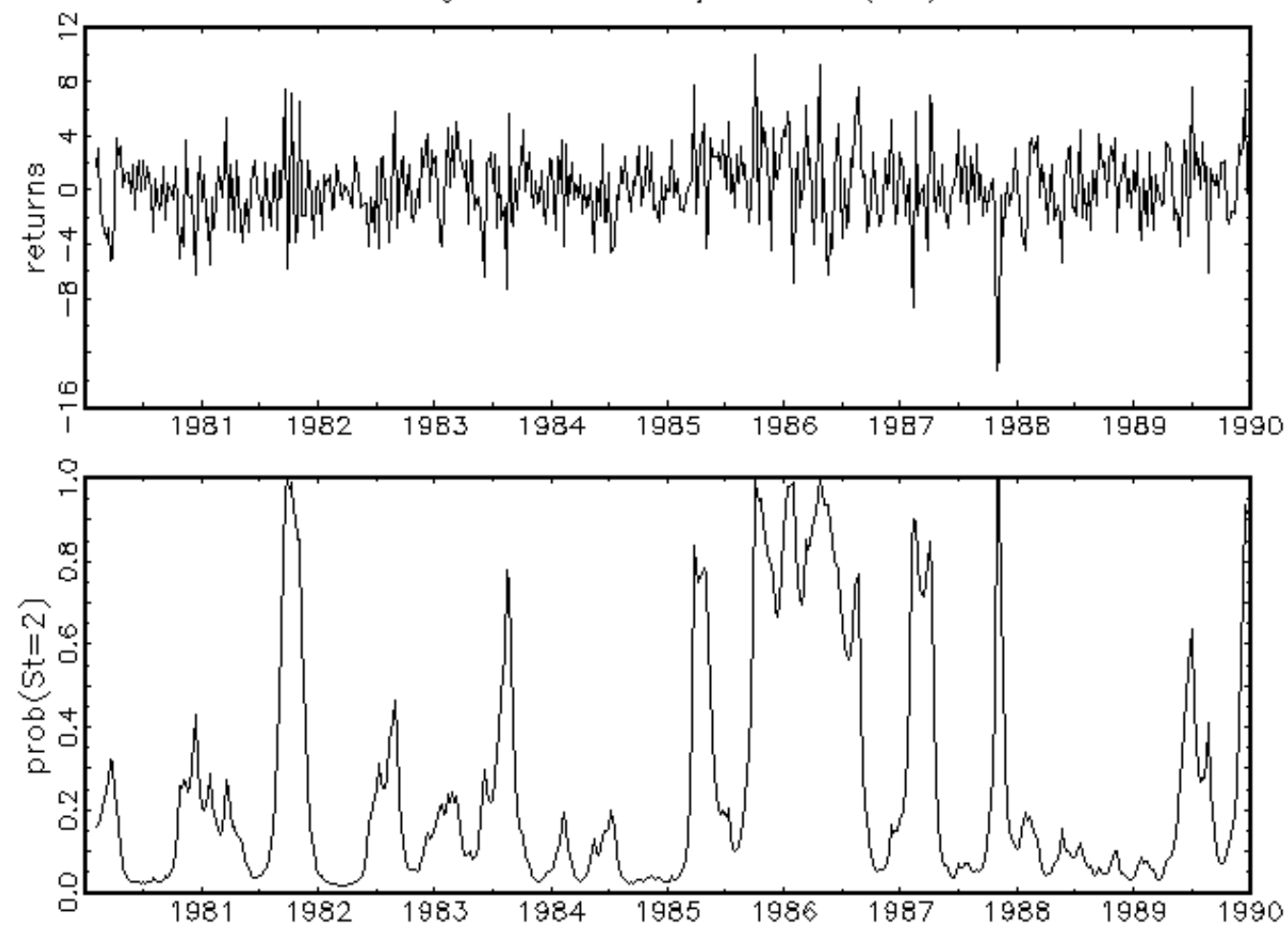
Figure 4: U.K. $\operatorname{SWARCH}(2,2)$
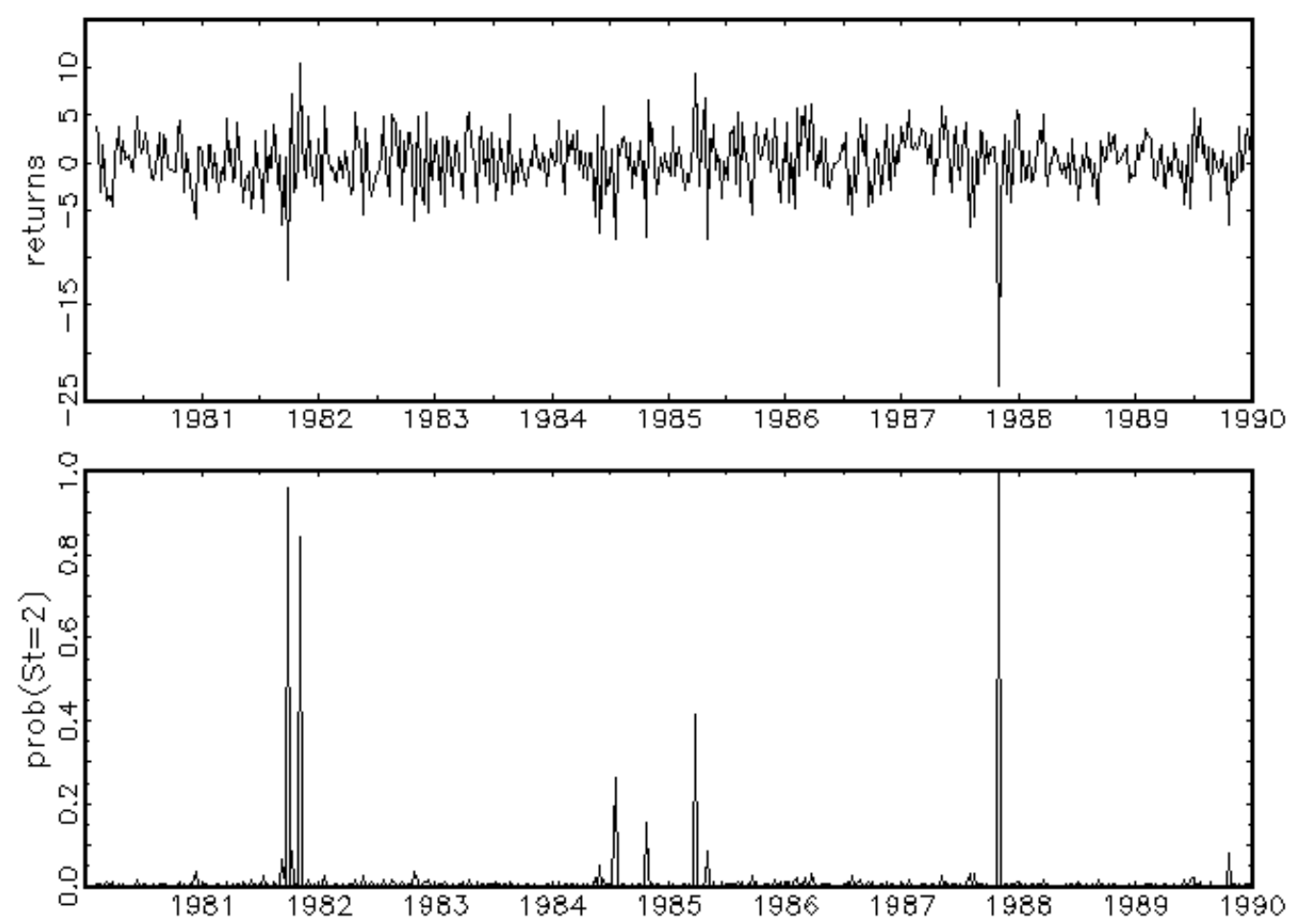
Figure 5: Japan $\operatorname{SWARCH}(2,2)$
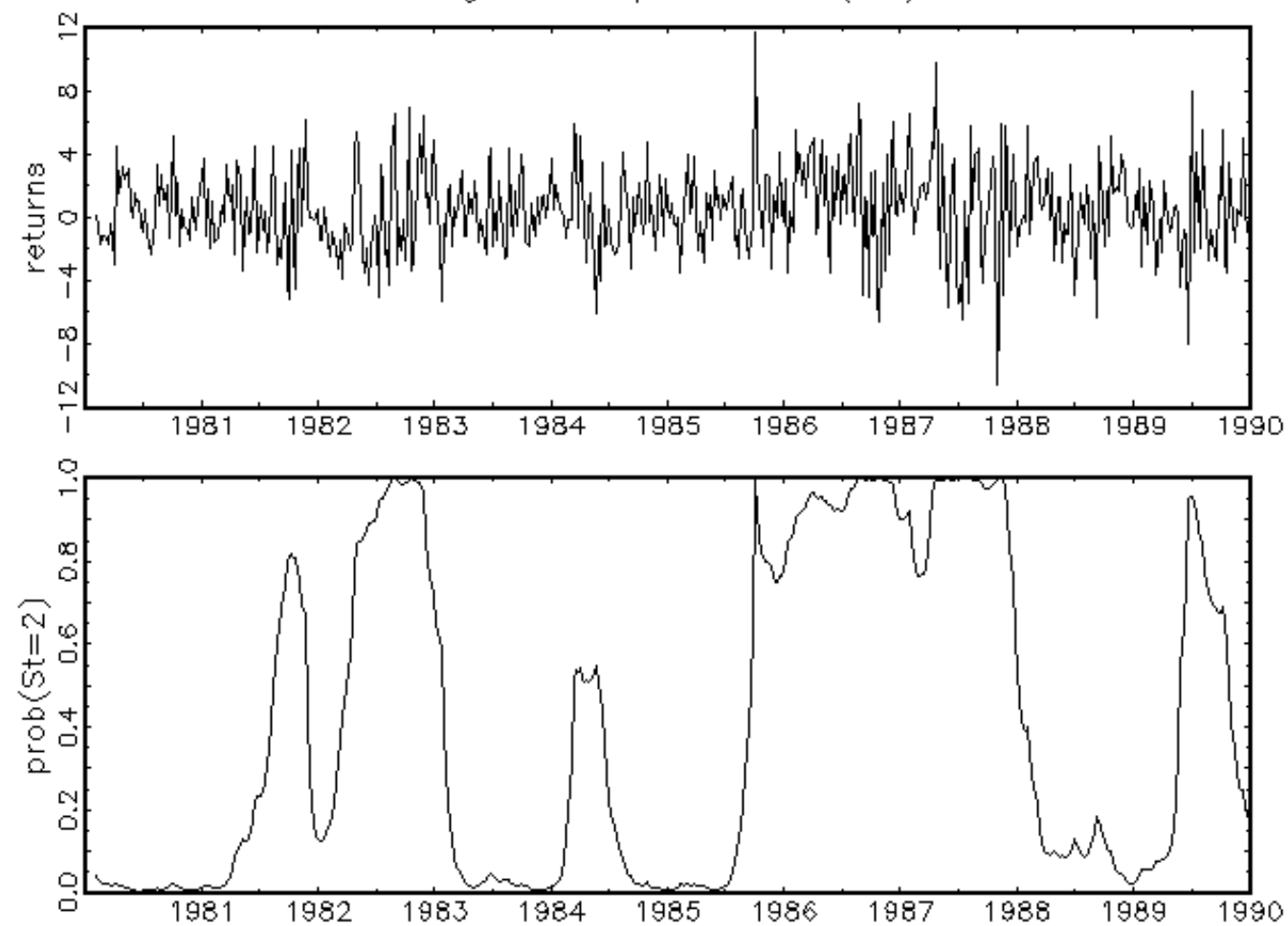
Figure 6: Australia $\operatorname{SWARCH}(2,2)$
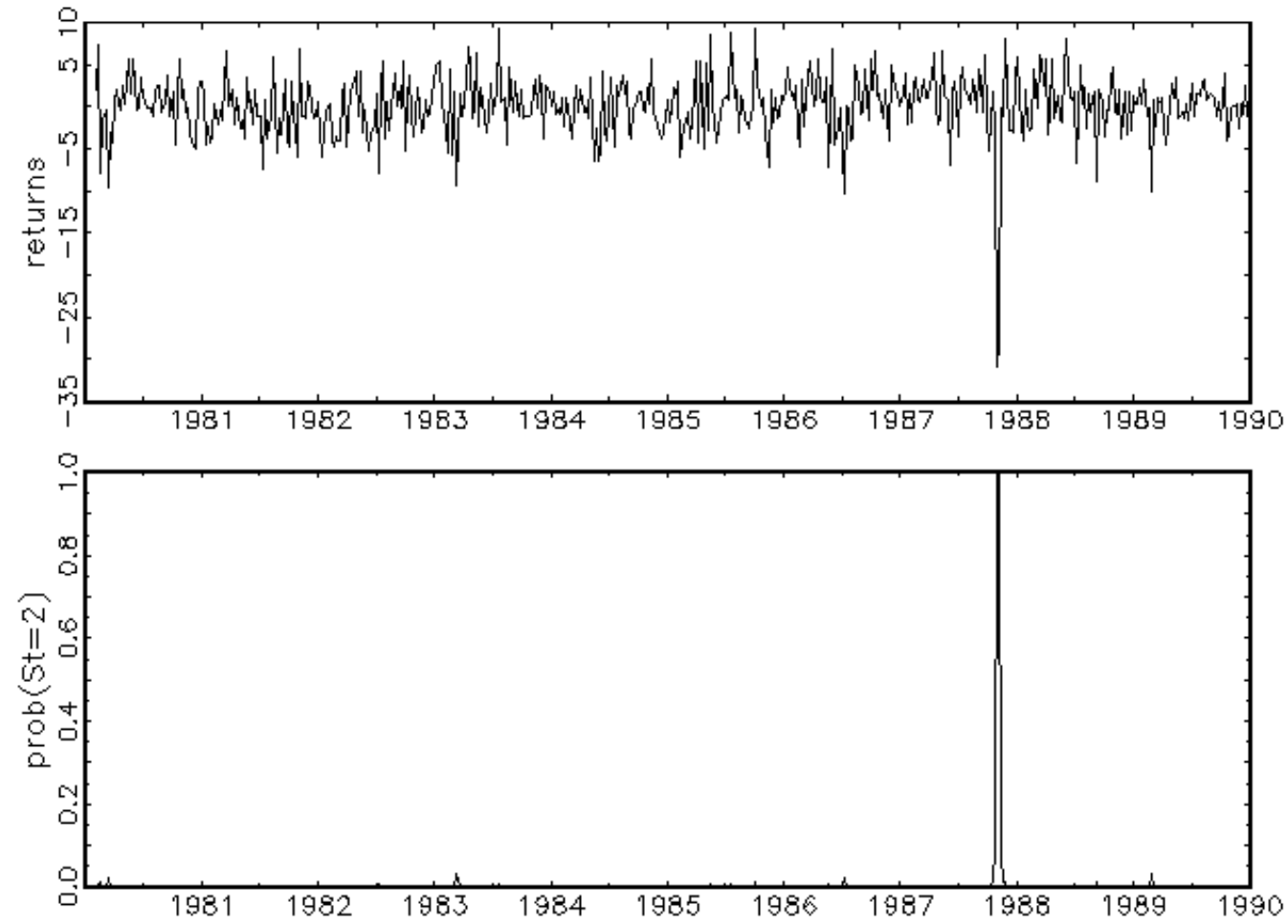

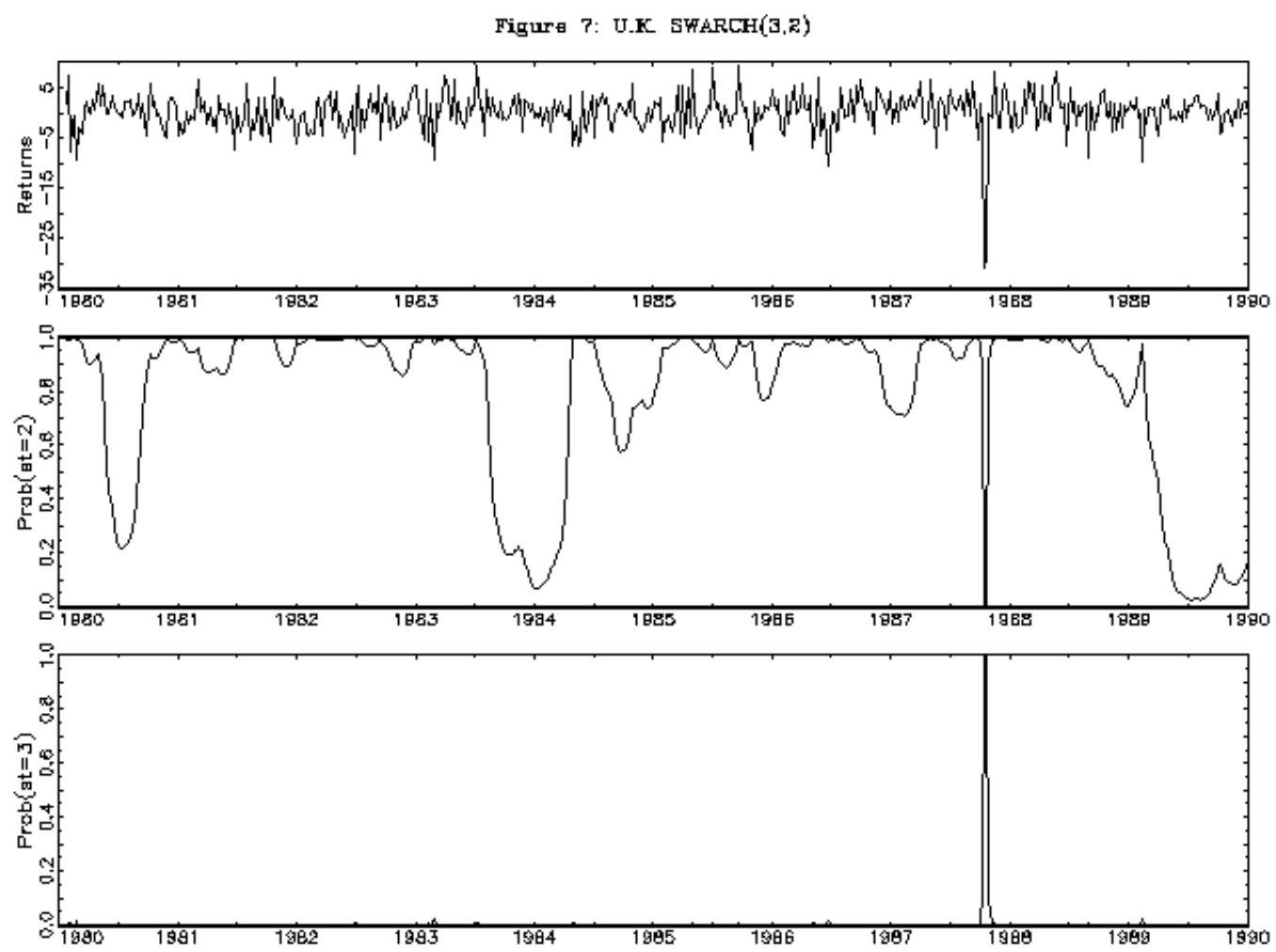
Figure 8: Australia STARCH(3, 2$)$
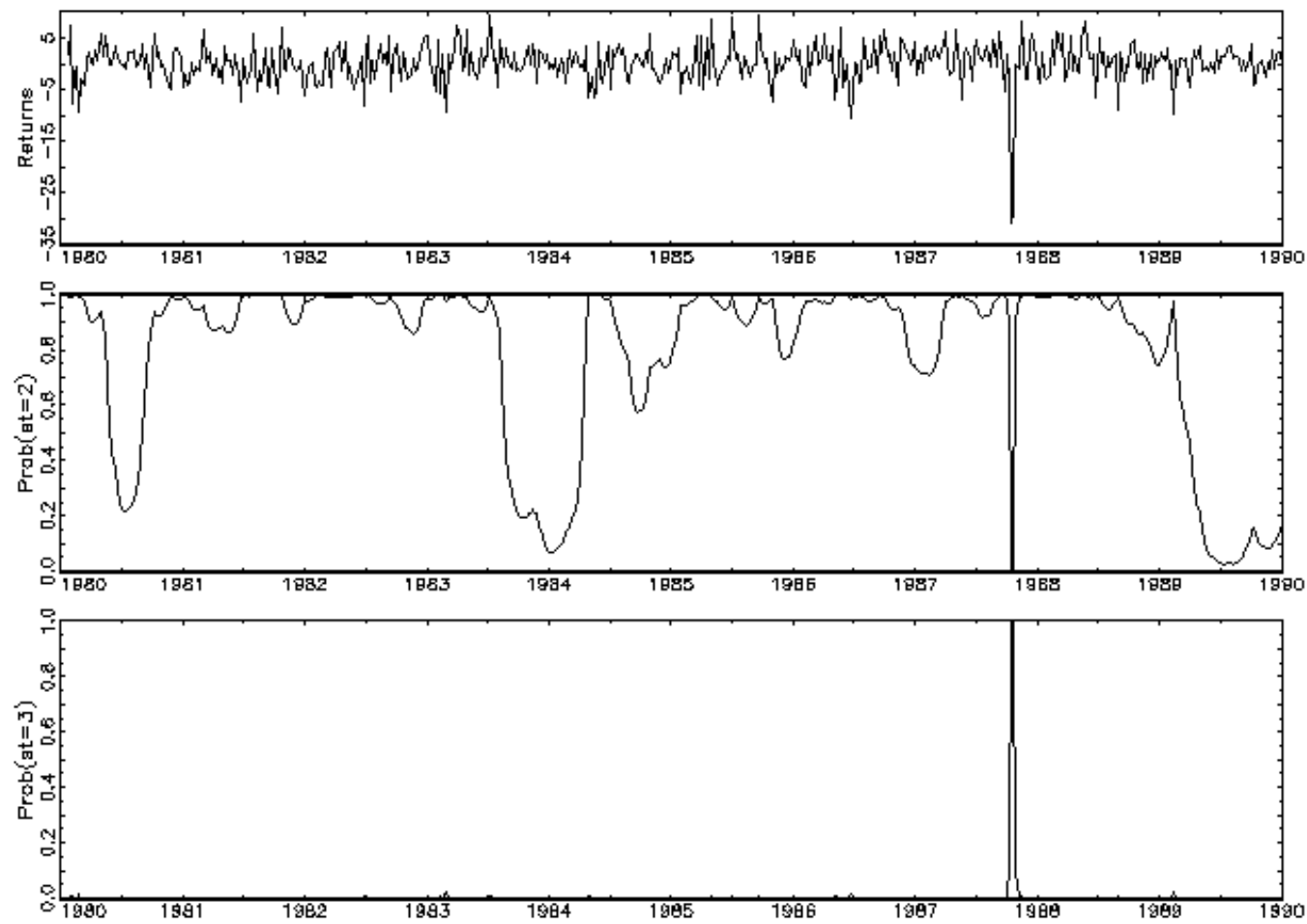